\title{
What is the role of putrescine accumulated under potassium deficiency?
}

Jing Cui ${ }^{1}$, Igor Pottosin ${ }^{2}$, Emmanuelle Lamade $^{3} \&$ Guillaume Tcherkez $^{1 *}$

1. Research School of Biology, ANU Joint College of Sciences, Australian National University, 2601 Canberra ACT, Australia.

2. Biomedical Centre, University of Colima, 28045, Colima, Mexico.

3. UPR34 Performance des systèmes de culture des plantes pérennes, Département PERSYST, Centre de Coopération Internationale en Recherche Agronomique pour le Développement (CIRAD), 34398 Montpellier, France.

*Contact author to whom correspondence should be addressed: guillaume.tcherkez@anu.edu.au

Short title: Putrescine roles under $\mathrm{K}^{+}$deficiency

Keywords: polyamines, potassium, deficiency, putrescine, ion balance

Twitter account: @IsoSeed

ORCID account: G. Tcherkez: https://orcid.org/0000-0002-3339-956X

Corresponding author

Guillaume Tcherkez

Research School of Biological Sciences

Australian National University

2601 Canberra ACT, Australia

guillaume.tcherkez@anu.edu.au

This article has been accepted for publication and undergone full peer review but has not been through the copyediting, typesetting, pagination and proofreading process which may lead to differences between this version and the Version of Record. Please cite this article as doi: $10.1111 /$ pce. 13740 


Abstract (178 words)
Biomarker metabolites are of increasing interest in crops since they open avenues for
precision agriculture, whereby nutritional needs and stresses can be monitored optimally.
Putrescine has the potential to be a useful biomarker to reveal potassium $\left(\mathrm{K}^{+}\right)$deficiency. In
fact, although this diamine has also been observed to increase during other stresses such as
drought, cold or heavy metals, respective changes are comparably low. Due to its multifaceted
biochemical properties, several roles for putrescine under $\mathrm{K}^{+}$deficiency have been suggested,
such as cation balance, antioxidant, reactive oxygen species (ROS) mediated signaling,
osmolyte, or pH regulator. However, the specific association of putrescine build-up with low
$\mathrm{K}^{+}$availability in plants remains poorly understood, and possible regulatory roles must be
consistent with putrescine concentration found in plant tissues. We hypothesize that massive
increase of putrescine upon $\mathrm{K}^{+}$starvation plays an adaptive role. A distinction of putrescine
function from that of other polyamines (spermine, spermidine) may be based either on its
specificity or (which is probably more relevant under $\mathrm{K}^{+}$deficiency) on a very high attainable
concentration of putrescine, which far exceeds those for spermidine and spermine. Excessive
putrescine and its catabolites appear to possess a strong potential in controlling cellular $\mathrm{K}^{+}$
and $\mathrm{Ca}^{2+}$, and mitochondria and chloroplasts bioenergetics under $\mathrm{K}^{+}$stress.




\section{Introduction}

Putrescine, spermine and spermidine are dominant polyamine species, naturally found in all organisms. It is now more than 65 years since putrescine was found to accumulate under $\mathrm{K}^{+}$ deficiency in plants (Richards \& Coleman, 1952; Coleman \& Richards, 1956; Coleman \& Hegartv, 1957). In fact, when $\mathrm{K}^{+}$availability is low or very low in the nutrient solution or in soil, putrescine accumulates in several parts of the plant, particularly in leaves, to levels that can be up to 150 times higher than the normal content under $\mathrm{K}^{+}$-sufficient conditions. As such, putrescine is one of the first metabolic biomarker that has been discovered in the history of plant physiology.

Biomarker metabolites that are tractable using metabolomics are of potential importance in crop management, not only to follow developmental stages but also to monitor disease progression, nutritional needs or abiotic stresses (for a recent review, see (Alexandersson et al., 2014)). Here, putrescine is an interesting candidate to detect $\mathrm{K}^{+}$ deficiency situations, as suggested back in the 80s (Smith, 1984). Leaf metabolic biomarkers would be extremely useful to adjust cropping practices and in particular, $\mathrm{K}^{+}$fertilization. In effect, the simple measurement of $\mathrm{K}^{+}$levels in leaves can be insufficient to characterize the ion status of crops and thus to detect $\mathrm{K}^{+}$deficiency. This is typically the case in oil palm (Elaeis guineensis, a high $\mathrm{K}^{+}$-demanding species) where variations in leaf potassium elemental content are relatively small even though $\mathrm{K}^{+}$availability may vary widely.

Putrescine is synthesized from ornithine, either via the direct route involving ornithine decarboxylase (ODC) or the indirect route that involves arginine decarboxylase (ADC) (Fig. 1) (Slocum, 2005). Metabolomics studies on Arabidopsis have suggested that putrescine and ornithine are positively correlated with growth (Meyer et al., 2007) and ADC activity is essential for root growth (Watson et al., 1998). In tobacco, the ODC pathway is believed to be related to growth and proliferation, whereas the ADC pathway seems to be associated with morphogenesis and stress response (Masgrau et al., 1997). However, the putrescine biosynthetic pathway depends on the plant species. For example, Arabidopsis lacks ornithine decarboxylase and thus synthesize putrescine from arginine only (Hanfrey et al., 2001). Most other species have both enzymes, with varying proportions of the biochemical route used. For example, in oil palm there is a quantitative decrease in ornithine with no appearance of intermediates (like arginine) when putrescine accumulates (Fig. S1a), suggesting that the direct route is used. Similarly, in sunflower leaves, both ornithine and putrescine accumulate under $\mathrm{K}^{+}$deficiency (Fig. S1b) and putrescine generally anticorrelates with arginine (Fig. S2), suggesting a competition between arginine and putrescine synthesis from ornithine and therefore, the direct route of putrescine biosynthesis. In response to low $\mathrm{K}^{+}$conditions, Poaceae generally synthesize putrescine via arginine decarboxylase (see, e.g., (Young \& Galston, 1984)).

Despite its widespread accumulation (Table 1), the precise role played by putrescine under $\mathrm{K}^{+}$deficiency remains somewhat enigmatic. There are several reasons to explain this limitation. First, several biochemical roles are in principle possible (described below). Second, putrescine (as other polyamines) has been found to accumulate (although to a lower extent and less systematically) under stress conditions other than $\mathrm{K}^{+}$deficiency, suggesting it 
is part of a more general stress response (Table 1). Third, putrescine accumulation is metabolically "expensive" because it requires ATP, redox power (NADPH) and assimilated nitrogen (that might be limiting under $\mathrm{K}^{+}$deficiency because of altered nitrate circulation). Using the direct route, the overall equation gives:

$$
2 \text { glutamate }+\mathrm{ATP}+\mathrm{NADPH} \rightarrow \text { putrescine }+\mathrm{CO}_{2}+2 \mathrm{OG}+\mathrm{NADP}+\mathrm{ADP}+\mathrm{Pi}
$$

where $20 \mathrm{OG}$ stands for 2-oxoglutarate. The overall equation with the indirect route is even more expensive in terms of consumed ATP, as follows (assuming that fumarate is recycled via NAD-dependent malate dehydrogenase and that carbamoyl phosphate is synthesized de novo):

2 glutamate $+4 \mathrm{ATP}+\mathrm{NADPH}+\mathrm{NAD} \rightarrow$ putrescine $+\mathrm{CO}_{2}+2 \mathrm{OG}+\mathrm{NADP}+\mathrm{NADH}+4(\mathrm{ADP}+$ $\mathrm{Pi})$

Considering such an energy requirement, the function of putrescine should be of considerable importance. In this short review, we briefly describe possible roles of putrescine, and summarize data that help defining most likely and specific roles of putrescine under $\mathrm{K}^{+}$ deficiency.

\section{Is putrescine a versatile biomarker of $\mathrm{K}$ deficiency?}

Putrescine accumulates under $\mathrm{K}^{+}$deficiency up to the 1-10 $\mathrm{mM}$ range, with an increase up to by two orders of magnitude as compared to its level at optimal $\mathrm{K}^{+}$(Table 1). For instance, in oil palm putrescine concentration is $c a .60 \mu \mathrm{M}$ at high $\mathrm{K}^{+}$and $1.8 \mathrm{mM}$ at low $\mathrm{K}^{+}$(i.e., $\approx 7$ $\mu \mathrm{mol} \mathrm{g} \mathrm{DW}{ }^{-1}$; Fig. S1) (Cui et al., 2019b). Conversely, high (>10 mM) external $\mathrm{K}^{+}$causes a decrease in putrescine content, which is converted to "higher polyamines" (this term refers to higher molecular weight polyamines synthesized from putrescine, such as spermine and spermidine) (Aurisano et al., 1993; Reggiani et al., 1993) and/or putrescine extrusion (Tamai et al., 2000). Thus, putrescine metabolism is sensitive to external $\mathrm{K}^{+}$, but the underlying mechanism is still unknown. It might be speculated that the increase in putrescine content at low $\mathrm{K}^{+}$is caused by the stimulation of ammonium assimilation (see high $\mathrm{NH}_{4}^{+}$conditions in Table 1), which has indeed been observed in Arabidopsis (Armengaud et al., 2009). Regardless of the underlying metabolic cause for its accumulation, putrescine seems to be a good low- $\mathrm{K}^{+}$biomarker in the bio-statistical sense since its increase is highly significant (order of magnitude of the $P$-value far below that of many other metabolites changed by low $\mathrm{K}^{+}$) and it has a very high weight (loading) in multivariate analyses. Therefore, it might be used as an index for $\mathrm{K}^{+}$availability (Cui et al., 2019a; Cui et al., 2019b).

Nevertheless, putrescine also may accumulate under other conditions, such as low $\mathrm{pH}$, anoxia, heavy metals, low $\mathrm{Mg}^{2+}$, cold or osmotic stress. In half of cases, putrescine has been found to decrease under salt stress (Table 1) and to confer no specific advantage for $\mathrm{NaCl}$ tolerance when applied exogenously (Ndayiragije \& Lutts, 2006). Polyamines other than putrescine (spermine, spermidine) may also accumulate under $\mathrm{K}^{+}$deficiency although not to the same extent and can even decrease (for an example in Arabidopsis, see (Watson \& Malmberg, 1996); see also Fig. S2 where neither spermine nor spermidine appear in significant metabolites). In fact, the biosynthesis of spermine and spermidine requires $\mathrm{S}$ - 
adenosyl methioninamine (SAE, Fig. 1), which is produced from S-adenosyl methionine (SAM) decarboxylation. SAM synthetase requires $\mathrm{K}^{+}$as a cofactor (Takusagawa et al., 1996) and therefore its activity is probably very limited under $\mathrm{K}^{+}$deficiency, thereby impacting not only polyamines, but also all cellular reactions that use SAM as a methyl donor. Also, in plants, it is remarkable that putrescine is not an effector of SAM decarboxylase activity (contrary to its mammalian counterpart) (Bennett et al., 2002) thereby allowing putrescine accumulation without stimulation of SAE (and thus spermine and spermidine) production. Phosphate deprivation has also been reported to trigger putrescine build-up (Knobloch \& Berlin, 1981; Shih \& Kao, 1996). However, in (Shih \& Kao, 1996) phosphate abstraction from the medium seems to have been done by withdrawing potassium phosphate from the nutrient solution, meaning that the build-up of putrescine was in fact coupled to $\mathrm{K}^{+}$ deficiency.

\section{One molecule, too many roles?}

Plant polyamines have been studied for a long time and quite understandably, the literature on polyamines in plant physiology is now considerable. Taken as a whole, polyamines are believed to be of importance under stressful conditions and to play a signaling role during plant development (Galston \& Sawhney, 1990; Alcázar et al., 2006; Tiburcio et al., 2014). Historically, putrescine has been suggested to play a role of $(i)$ a cation to substitute $\mathrm{K}^{+}$, $(i i)$ an antioxidant and/or a ROS-mediated signal (via oxidation), (iii) an osmolyte under salt or osmotic stress, (iv) a root-shoot transport molecule (either as a nitrogen-containing metabolite or a cation), and ( $v)$ a cryoprotectant at low temperature. However, ionomics analyses have shown that when compared to other cations, putrescine represents a small pool $(<5 \%)$ of positive charges (Fig. 2), so its role in charge balance is minor and the same is true for its role in osmoprotection. The role of antioxidant, although widely supported experimentally, seems to depend on concentration and conditions, since there are examples where polyamine addition may trigger oxidative stress (Mohapatra et al., 2009) and polyamine catabolism is indeed an important source of hydrogen peroxide and other ROS species, especially under stress conditions (Moschou et al., 2008; Pottosin et al., 2014b; Wang et al., 2019) (see also Concurrent effects of putrescine below). In the next sections, we focus on roles of putrescine, as compared to higher polyamines, in the regulation of $\mathrm{K}^{+}$acquisition and re-distribution, $\mathrm{Ca}^{2+}$ signaling, and chloroplast and mitochondrion functions.

\section{Putrescine and regulation of cation transport and balance}

\section{Consequences of $K^{+}$deficiency for ion composition}

$\mathrm{K}^{+}$deficiency is not associated with a general decrease, but actually leads to a significant increase in cation load (Fig. 2, insets). That is, quite counter-intuitively, $\mathrm{K}^{+}$deficiency implies an extra demand in negative charges to reach electro-neutrality, which is met by accumulated organic and amino acids (Armengaud et al., 2009). The excess of positive charges mostly comes from the considerable increase in $\mathrm{Ca}^{2+}$ (up to 2-fold increase) and $\mathrm{Mg}^{2+}$ (more than 2fold) in oil palm and sunflower (Cui et al., 2019a; Cui et al., 2019b). Under $\mathrm{K}^{+}$deficiency, there is also an increase in the difference between $\mathrm{Ca}^{2+}$ and the sum $\mathrm{Mg}^{2+}+\mathrm{K}^{+}$(of about 0.4 mmol positive charges $\mathrm{g}^{-1} \mathrm{DW}$ in Fig. 2). In general, there is a well-supported negative 
relationship between $\mathrm{K}^{+}$and $\mathrm{Ca}^{2+}$, which has been documented for nearly 50 years in herbaceous crops (such as sunflower, rapeseed, tobacco, or wheat). This is here examplified in oil palm, cultivated under varying $\mathrm{K}^{+}$fertilization (Fig. S3). Similarly, in other species such as castor bean, $\mathrm{K}$ deficiency causes an increase in $\mathrm{Ca}^{2+}$ and $\mathrm{Mg}^{2+}$, and a slight decrease in $\mathrm{Na}^{+}$in leaf lamina, but conversely a considerable increase in $\mathrm{Na}^{+}$with little change in $\mathrm{Ca}^{2+}$ and $\mathrm{Mg}^{2+}$ in petioles and phloem sap, leading to an excess of positive charges (Peuke et al., 2002). In grape, low $\mathrm{K}^{+}$is compensated for by $\mathrm{Ca}^{2+}$ and $\mathrm{Mg}^{2+}$ in leaves and by $\mathrm{Na}^{+}$in fruits also suggesting that phloem sap carries more $\mathrm{Na}^{+}$(Ruhl, 1989). While these effects reflect the antagonism between $\mathrm{K}^{+}, \mathrm{Na}^{+}$and $\mathrm{Mg}^{2+}$ absorption and exchange (Diem \& Godbold, 1993; Jakobsen, 1993), they also show that $\mathrm{K}^{+}$deficiency is associated with more positive charges in the phloem, and thus that putrescine is unlikely to play the role as a cation to substitute $\mathrm{K}^{+}$ in sap. However, when $\mathrm{K}^{+}$deficiency is compensated for by $\mathrm{K}^{+}$-substitution with $\mathrm{Na}^{+}$or $\mathrm{Rb}^{+}$, putrescine accumulates less, suggesting that there is a link with cations (Richards \& Coleman, 1952; Smith, 1984). Quite remarkably, if $\mathrm{K}^{+}$-deficiency is accompanied by low $\mathrm{Ca}^{2+}$ provision, putrescine accumulation is also lower (Richards \& Coleman, 1952; Coleman \& Richards, 1956). These observations suggest that putrescine is mostly a response to a disequilibrium in cation composition, in which $\mathrm{Ca}^{2+}$ would be over-represented. $\mathrm{Mg}^{2+}$ deficiency also leads to a modest putrescine accumulation (Table 1), probably because it changes the cation balance in favor of $\mathrm{Ca}^{2+}$, but to a lower extent than $\mathrm{K}^{+}$deficiency (due to the naturally lower $\mathrm{Mg}^{2+}$ content compared to $\mathrm{K}^{+}$; for example, see Fig. 2).

\section{Regulation of $\mathrm{H}^{+}$-ATPases by putrescine}

Rather than acting as a charge-balancing cation, putrescine appears to regulate the cation balance (summarized in Fig. 3). Lowering external $\mathrm{K}^{+}$concentration causes a rapid (within minutes) membrane hyperpolarization, which stimulates $\mathrm{K}^{+}$uptake via inward-rectifying AKT1 channels (Chérel et al., 2013; Wang \& Wu, 2013). When $\mathrm{K}^{+}$starvation lasts, however, membrane depolarization may occur, which correlates with a marked decrease in cytosolic $\mathrm{K}^{+}$ concentration (Armengaud et al., 2009). To drive $\mathrm{K}^{+}$uptake, the activity of root $\mathrm{K}^{+} / \mathrm{H}^{+}$ symporter (mainly via HAK5) energized by plasma membrane $\mathrm{H}^{+}$-ATPase is critical (Wang $\& \mathrm{Wu}, 2013)$. Potassium ions uncouple ATP hydrolysis from the $\mathrm{H}^{+}$extrusion in plasma membrane $\mathrm{H}^{+}$-ATPase (Buch-Pedersen et al., 2006). Thus, at low cytosolic $\mathrm{K}^{+}$, ATP/ $\mathrm{H}^{+}$ coupling is probably better and $\mathrm{H}^{+}$extrusion is stimulated, thereby favoring ion uptake (Chérel et al., 2013; Wang \& Wu, 2013). Then do polyamines and putrescine in particular, influence plasma membrane $\mathrm{H}^{+}$-ATPase? The answer to this question appears to be speciesand tissue-dependent. Suppression of both plasma membrane and vacuolar $\mathrm{H}^{+}$-ATPase activity was observed in cucumber roots pretreated for $24 \mathrm{~h}$ with either putrescine, spermine or spermidine (Janicka-Russak et al., 2010). In that case, the inhibition was caused by a decrease in the expression for an $\mathrm{H}^{+}$-ATPase isoform and not by a direct (physical) interaction affecting ATPase catalysis. In rice coleoptiles, direct stimulation of plasma membrane $\mathrm{H}^{+}-$ pumps by all polyamines at millimolar $(\mathrm{mM})$ concentration has been reported, while only putrescine may reach such a concentration in physiological situations (Reggiani et al., 1992). In maize roots, plasma membrane $\mathrm{H}^{+}$-pumping is rapidly stimulated by putrescine (in the elongation zone) and depressed by spermine (in the maturation zone) (Pandolfi et al., 2010). 
Similarly, spermine at high concentrations suppresses, whereas putrescine has no direct effect, on $\mathrm{H}^{+}$-pumping in plasma membrane vesicles isolated from pea roots (Pottosin et al., 2014a). This contrasted effect of putrescine and other polyamines on $\mathrm{H}^{+}$-ATPases could originate from difference in competing with $\mathrm{Mg}^{2+}$ for ATP-binding and/or ATPase phosphorylation. In fact, putrescine does not bind to ATP, but spermine does (Igarashi et al., 1989) while MgATP (and not free ATP) acts as a substrate for $\mathrm{H}^{+}$-ATPases. In intact roots, both polyamines induced $\mathrm{Ca}^{2+}$-pumping, which in turn stimulated $\mathrm{H}^{+}$-pumping, most likely via a decrease of $\mathrm{H}^{+}$-ATPase protein phosphorylation by a $\mathrm{Ca}^{2+}$-dependent kinase (see (Pottosin et al., 2014a) and references therein). Thus, putrescine stimulates $\mathrm{H}^{+}$-pumping whereas spermine stimulates ATPase at low concentration and suppresses $\mathrm{H}^{+}$-pumping at high concentration. Taken as a whole, putrescine seems to favor $\mathrm{H}^{+}$-pumping across the plasma membrane unlike higher polyamines (spermine).

\section{Putrescine, ROS and $K^{+}$transport}

Externally applied polyamines at relatively high $(0.5-1 \mathrm{mM})$ concentration inhibit both inward and outward rectifying $\mathrm{K}^{+}$-selective currents in roots (Zhao et al., 2007; Pottosin, 2015), whereas internal polyamines at $1 \mathrm{mM}$ halved the current mediated by KAT1 in guard cells (Liu et al., 2000). It is not very likely, therefore, that these effects have a huge significance for $\mathrm{K}^{+}$absorption and retention. On the other hand, a combination of polyamines with oxidative stress induces a substantial $\mathrm{K}^{+}$loss from roots. ROS are produced via the oxidation of putrescine and other polyamines by intrinsic apoplast diamine and polyamine oxidases (DAO and PAO, respectively) (DiTomaso et al., 1989; Zepeda-Jazo et al., 2011; Velarde-Buendía et al., 2012; Pottosin et al., 2014b). The occurrence of DAO and PAO is variable, with DAO being more abundant in Dicots and PAO in Monocots like Poaceae (Moschou et al., 2008). The loss of $\mathrm{K}^{+}$, especially in specialized zones like the root apex, is not necessarily harmful despite oxidative stress. Instead, low intracellular $\mathrm{K}^{+}$may be sensed and induce a metabolic switch to defense responses (Shabala, 2017). Another product of putrescine catabolism, GABA, has recently been shown to improve $\mathrm{K}^{+}$retention in Arabidopsis roots by a stimulation of plasma membrane $\mathrm{H}^{+}$-ATPase activity, a decrease of stress-induced ROS production and a decrease in the expression of outward-rectifying $\mathrm{K}^{+}$channel, GORK ( $\mathrm{Su}$ et al., 2019).

\section{Putrescine and $\mathrm{Ca}^{2+}$ homeostasis}

Overall, the cation load as well as total $\mathrm{Ca}^{2+}$ increase under $\mathrm{K}^{+}$deficiency (e.g. Fig. 2 and S3). Free cytosolic $\mathrm{Ca}^{2+}$ may be kept low by $(i)$ efficient $\mathrm{Ca}^{2+}$ extrusion while as mentioned above, there is a stimulation of plasma membrane $\mathrm{Ca}^{2+}$ pumps by polyamines; and (ii) vacuolar $\mathrm{Ca}^{2+}$ sequestration. The latter is especially important, bearing in mind the observed increase in total $\mathrm{Ca}^{2+}$ because in plant cells, total cellular $\mathrm{Ca}^{2+}$ mostly reflects vacuolar $\mathrm{Ca}^{2+} \cdot \mathrm{Ca}^{2+}$ accumulates in vacuoles via $\mathrm{CAX}$-mediated $\mathrm{H}^{+} / \mathrm{Ca}^{2+}$ antiport, fueled by the trans-tonoplast $\mathrm{H}^{+}$gradient. To ensure efficient vacuolar $\mathrm{Ca}^{2+}$ retention, channel-mediated $\mathrm{Ca}^{2+}$ loss from the vacuole to the cytosol must be negligible. SV/TPC1 channels are the major routes of vacuolar $\mathrm{Ca}^{2+}$ release (Pottosin \& Schönknecht, 2007). Consequently, relative expression of TPC1 and CAX is 
crucial for vacuolar $\mathrm{Ca}^{2+}$ accumulation (Gilliham et al., 2011). Importantly, ionic currents via SV channels are efficiently suppressed by polyamines in their physiological range of concentrations. Albeit this effect is charge-dependent, with putrescine having the lowest affinity (Dobrovinskaya et al., 1999b), it could be compensated for by a very high putrescine concentration under $\mathrm{K}^{+}$deprivation.

\section{Putrescine and vacuole-cytosol $K^{+}$balance}

Under $\mathrm{K}^{+}$deficiency, maintenance of relatively high cytosolic $\mathrm{K}^{+}$is achieved at the expense of the vacuolar $\mathrm{K}^{+}$(Walker et al., 1996). In the initial phase, vacuole will indeed compensate for the decrease in cytosolic $\mathrm{K}^{+}$by $\mathrm{K}^{+}$-release via selective (TPK) and non-selective monovalent cation FV channels, both marginally sensitive to putrescine at the sub-millimolar range (Brüggemann et al., 1998; Dobrovinskaya et al., 1999a; Hamamoto et al., 2008). Under very strong $\mathrm{K}^{+}$deprivation, the electrochemical gradient for $\mathrm{K}^{+}$becomes vacuole-directed (Walker et al., 1996). Thus, to minimize passive vacuolar $\mathrm{K}^{+}$re-uptake, it is certainly crucial to reduce $\mathrm{K}^{+}$-transport by $\mathrm{K}^{+}$-permeable channels. When putrescine reaches millimolar concentration, $\mathrm{K}^{+}$transport not only via $\mathrm{SV}$ channels but also via $\mathrm{FV}$ channels will be suppressed (Brüggemann et al., 1998; Dobrovinskaya et al., 1999a).

\section{Roles of putrescine in chloroplasts}

Possible roles of putrescine on chloroplast metabolism are summarized in Fig. 4. Subcellular fractionation followed by metabolomics analysis has shown that about $40 \%$ of cellular putrescine is present in chloroplasts in Arabidopsis leaves (Krueger et al., 2011), perhaps reflecting the activity of chloroplastic ADC (Borrell et al., 1995; Bortolotti et al., 2004). Stress-induced stimulation of ADC (Alcázar et al., 2010) might further increase putrescine accumulation in chloroplasts. In chloroplasts, polyamines are believed to regulate different aspects of photosynthesis, with reported differences in action between putrescine and other polyamines. Exogenous putrescine decreases non-photochemical quenching (NPQ) and increases photochemical yield (Ioannidis et al., 2006). Yet, these results have been obtained under non-physiological conditions, with a low-salt medium, to minimize the interference with other cations ( such as $\mathrm{Mg}^{2+}$ ) and therefore, are perhaps not so informative. On the other hand, with more physiological saline buffers, all polyamines stimulate photophosphorylation at low concentrations, whereas spermidine and spermine but not putrescine act as strong uncouplers at high concentration ( $>1 \mathrm{mM}$ for spermidine and $>0.1 \mathrm{mM}$ for spermine). That is, only putrescine induces a relatively high and stable stimulation of ATP production in chloroplasts (Ioannidis \& Kotzabasis, 2007).

Putrescine is a weak base $\left(\mathrm{pK}_{\mathrm{a}}\right.$ 10.8) thus its uncharged form coexist, albeit at a relatively small fraction $(0.04 \%)$, with the charged species at $\mathrm{pH}$ 7.4. Light induces stromal alkalization and thylakoid lumen acidification and this proton gradient can be damped by transport of uncharged putrescine across the thylakoid membrane. This does not affect the electrical potential difference across the thylakoid membrane $(\Delta \Psi)$ but dissipates $\Delta \mathrm{pH}$ and reduces lumen acidification, optimizing photosynthesis under stress conditions where high 
$\Delta \mathrm{pH}$ values lead to NPQ (Ioannidis et al., 2012). Under $\mathrm{K}^{+}$deficiency, the decrease in $\mathrm{K}^{+}$can be compensated for by an increase in $\mathrm{Mg}^{2+}$ (Fig. 2). $\mathrm{Mg}^{2+}$ is a charge-balancing cation that can dissipate $\Delta \Psi$ and facilitate $\Delta \mathrm{pH}$ built-up across the thylakoid membrane via $\mathrm{Mg}^{2+}$ permeable channels that are present in thylakoid membranes (Pottosin \& Schönknecht, 1996). Thus, putrescine can have a role of $\mathrm{Mg}^{2+}$ antagonist, whereby it prevents excessive energy dissipation and decreased photosynthesis, which may be due to the excessive lumen acidification even at relatively low light (see (Davis et al., 2017), for further details). It has also been demonstrated that putrescine up-regulates the expression of ATP-synthase and exerts a general protective effect on the photosynthetic membrane and in particular PSII structure (Shu et al., 2015).

\section{Roles of putrescine in mitochondria}

Putrescine is synthesized outside mitochondria but can be taken up by them. It is likely exchanged between the cytosol and the mitochondrial matrix via a basic amino acid transporter which is able to carry arginine, citrulline, and ornithine (Hoyos et al., 2003; Palmieri et al., 2006). In animal cells, mitochondrial putrescine uptake has a low affinity $\left(K_{0.5}\right.$ $\approx 1-4 \mathrm{mM}$ ) but a high capacity driven by electrical gradient, i.e., the high negative potential of the mitochondrial matrix (Toninello et al., 1992; Dalla Via et al., 1999). Similarly, in plants, polyamine accumulation in mitochondria depends on membrane potential, but its regulation differs somewhat from that in animals (Pistocchi et al., 1990) and associated molecular mechanisms remain unknown (Fujita \& Shinozaki, 2015). Polyamines have diverse effects in mitochondria, typically on metabolism, electron transport and the permeability transition (summarized in Fig. 4).

\section{Putrescine and mitochondrial metabolism}

Under stress conditions, putrescine causes a stimulation of the tricarboxylic acid pathway (TCAP) and thus facilitate mitochondrial ATP production (Zhong et al., 2016). So far, this effect has been demonstrated for salt stress, when putrescine was supplied exogenously. This still needs to be tested under $\mathrm{K}^{+}$deficiency, based on large amounts of putrescine accumulated naturally. However, metabolomics analyses have suggested that the increased $\mathrm{CO}_{2}$ release under $\mathrm{K}^{+}$deficiency is not associated with a higher ATP production but rather reflects lower efficiency of the TCAP when $\mathrm{K}^{+}$is limiting enzymatic activity (Cui et al., 2019a). Also, it should be noted that mitochondrial carbonic anhydrase, which might play an important role in anaplerosis (conversion of catabolic $\mathrm{CO}_{2}$ into bicarbonate), is inhibited with a high affinity (low $K_{i}$ ) by spermine and spermidine, while putrescine has no effect (Carta et al., 2010).

Interestingly, tobacco mitochondrial complex I mutants, which have a slow growth phenotype, show a significant increase in putrescine, along with related compounds such as GABA (Lothier et al., 2019). At physiologically attainable $\mathrm{K}^{+}$, higher polyamines inhibit mitochondrial membrane-bound $\mathrm{F}_{0} \mathrm{~F}_{1}$-ATPase in Vigna (Peter et al., 1981), which may be partly caused by the fact that higher polyamines (but not putrescine) are able to displace $\mathrm{Mg}^{2+}$ from Mg-ATP complexes (Igarashi et al., 1989). That is, putrescine can activate 
mitochondrial $\mathrm{F}_{0} \mathrm{~F}_{1}$-ATPases even at low $\mathrm{K}^{+} / \mathrm{Na}^{+}$(in contrast to spermine and spermidine, the action of which decreases at low $\mathrm{K}^{+} / \mathrm{Na}^{+}$) (Peter et al., 1981) thereby allowing ATP production despite low $\mathrm{K}^{+}$concentration encountered under potassium deficiency. In addition, enzymatic transglutaminase covalent binding of putrescine to mitochondrial membrane proteins is associated with higher $\mathrm{F}_{0} \mathrm{~F}_{1}$-ATPase activity and tolerance to osmotic stress (Votyakova et al., 1999; Liu \& Zhang, 2004). Putrescine, albeit with a 100 times lower affinity compared to higher polyamines (yet with $K_{0.5}=0.3 \mathrm{mM}$ ), stimulates the activity of the mitochondrial membrane ATP/ADP exchanger (Krämer et al., 1986). This activation may become significant under $\mathrm{K}^{+}$deficiency, when putrescine reaches millimolar levels.

\section{Putrescine and mitochondrial membrane permeability}

Polyamines can have an impact on mitochondrial transmembrane potential $(\Delta \Psi)$, perhaps mediated by their effect on mitochondrial ATP-sensitive $\mathrm{K}^{+}$channels ( ${ }^{\text {mito }} \mathrm{K}_{\mathrm{ATP}}$ ). Both the molecular identity of ${ }^{\text {mito }} \mathrm{K}_{\text {ATP }}$ and their structural similarity with plasma membrane $\mathrm{K}_{\text {ATP }}$ channels (which are abundant in animal tissues but absent in plants) are still a matter of debate (Szabo \& Zoratti, 2014; Trono et al., 2015). Under the assumption that ${ }^{\text {mito }} \mathrm{K}_{\text {ATP }}$ are structurally similar to $\mathrm{K}^{+}$inward rectifiers (as animal plasma membrane $\mathrm{K}_{\text {ATP }}$ channels are), the $\mathrm{K}^{+}$current through the channel pore would be modulated in a voltage-dependent manner by cytosolic polyamines. In Mammals, spermine, spermidine and putrescine can regulate the $\mathrm{K}^{+}$efflux upon depolarization (Aguilar-Bryan \& Bryan, 1999). Unlike their animal counterparts, plant $\mathrm{K}_{\mathrm{ATP}}$ are not sensitive to $\mathrm{Mg}^{2+}$ (Pastore et al., 1999) but to our knowledge, the effect of polyamines has not been documented yet. Mitochondrial depolarization by $\mathrm{K}^{+}$ influx is believed to reduce ROS production in plants under stress (Trono et al., 2015) and, vice versa, hyperpolarization is associated with excessive electron pressure in the mitochondrial electron transfer chain (mETC) and higher ROS production. For example, under osmotic stress, a ROS-mediated activation of $\mathrm{K}_{\mathrm{ATP}}{ }^{+}$has been found in wheat (Trono et al., 2015). Thus, activation of plant ${ }^{\text {mito }} \mathrm{K}_{\mathrm{ATP}}$ could in principle be efficient to regulate mitochondrial activity, since it not only decreases $\Delta \Psi$ but also impedes ROS generation.

The effect of polyamines and in particular putrescine on mitochondria can also be linked to the control of mitochondrial permeability transition (MPT), which is a massive increase in permeability of the inner mitochondrial membrane, with a collapse of $\Delta \Psi$ and release of pro-apoptotic factors (cytochrome c). In effect, MPT with properties similar to those found in animal MPT, such as activation by $\mathrm{Ca}^{2+}$ overload and ROS, and inhibition by $\mathrm{Mg}^{2+}$ and low $\mathrm{pH}$, has been reported in plants and shown to promote programmed cell death (Fortes et al., 2001; Arpagaus et al., 2002; Tiwari et al., 2002; Lin et al., 2005; Scott \& Logan, 2008). Potentially, polyamines can have an action on MPT via electron pressure on mETC, $\mathrm{Ca}^{2+}$ concentration, and ROS generation.

In fact, MPT is stimulated by the increase in $\mathrm{Ca}^{2+}$ via $\mathrm{ROS}$ generation while polyamines have been found to mitigate ROS generation and inhibit MPT in both plants and animals (Tabor, 1960; Arpagaus et al., 2002; Toninello et al., 2004). While, unlike spermine, putrescine has been shown to be inefficient on cytochrome c release at up to $1 \mathrm{mM}$ in mitochondria isolated from rat heart (Stefanelli et al., 2000). the intermediate of putrescine synthesis, agmatine (Fig. 1), inhibits $\mathrm{Ca}^{2+}$-mediated MPT in Mammals (Battaglia et al., 2010). 
Conversely, in yeast, spermine stimulates $\mathrm{Ca}^{2+}$ uptake by mitochondria, thereby favoring MPT (Votyakova et al., 1993).

Polyamines at a physiological concentration $(0.1 \mathrm{mM})$ lead to a reduction of $\Delta \Psi$ by 30 and 50\%, with putrescine and spermine respectively; this differential effect of putrescine and spermine has been found to correlate with substrate preference of mitochondrial amine oxidase (Maccarrone et al., 2001) but whether this effect is effectively mediated by amine oxidase is not known. In plant mitochondria under low cytosolic cation load (low $\mathrm{K}^{+}$), putrescine slightly stimulates external $\mathrm{NAD}(\mathrm{P}) \mathrm{H}$ dehydrogenases while at high cation load, it has little effect; this is in contrast with spermidine and spermine, which stimulate $\mathrm{NAD}(\mathrm{P}) \mathrm{H}$ dehydrogenases activity considerably at low cation load (and inhibit dehydrogenases activity at high cation load) (Phelps \& McDonald, 1990; Rugolo et al., 1991; Sjölin \& Møller, 1991). Therefore, when $\mathrm{K}^{+}$concentration is low, spermine and spermidine tend to increase the electron pressure on the mETC and promotes ROS generation, while this effect does not take place with putrescine.

Surprisingly, although polyamines can inhibit MPT at relatively high concentration, they may also favor $\mathrm{Ca}^{2+}$ accumulation in the mitochondrial matrix, which normally acts as a MPT inducer (reviewed in (Toninello et al., 2004)). Thus, under $\mathrm{K}^{+}$deficiency, high putrescine concentration with higher $\mathrm{Ca}^{2+}$ load (MPT promoter) and high $\mathrm{Mg}^{2+}$ (MPT opposer) may either stimulate or down-regulate MPT, depending on whether the change in mitochondrial $\mathrm{Ca}^{2+}$ predominates over $\mathrm{Mg}^{2+}$ change, ROS limitation and electron pressure mitigation. Alternatively, one might speculate that a brief MPT event may have a protective role, releasing excess ROS and $\mathrm{Ca}^{2+}$ from the matrix and restoring normal mitochondrial ATP production. However, the release of ROS and $\mathrm{Ca}^{2+}$ may become self-propagative, causing $\mathrm{Ca}^{2+}$-induced $\mathrm{Ca}^{2+}$ release and ROS-induced ROS release (Zorov et al., 2014) and ultimately cell death. It is thus more likely that putrescine accumulation under $\mathrm{K}^{+}$deficiency is beneficial due to its combination of physiological effects, that is, simultaneous limitation of $\mathrm{Ca}^{2+}$ release in the cytosol (see above, Putrescine and $\mathrm{Ca}^{2+}$ homeostasis) and down-regulation of MPT.

\section{Side effects of putrescine}

The beneficial effects of putrescine in particular on cation balance (see above) probably explain why the addition of exogenous putrescine or the production of endogenous putrescine in transgenics has often been described as being advantageous to improve stress tolerance and mitigate oxidative stress (Öztürk \& Demir, 2003; Verma \& Mishra, 2005; Ndayiragije \& Lutts, 2006). However, overexpression of ADC2 in Arabidopsis induces dwarfism and late flowering (Alcázar et al., 2005). Also, overexpression of oat $A D C$ in tobacco leads to short internodes, thin stems and leaves, leaf chlorosis and necrosis, and reduces root growth (Masgrau et al., 1997), which mimics to some extent the symptoms of some stresses like $\mathrm{K}^{+}$ deficiency or osmotic shock. Conversely, inhibiting putrescine synthesis using D-arginine under phosphorus deficiency appears to be beneficial for total biomass in cultured rice cells (Shih \& Kao, 1996). It should be recognized that adding putrescine or boosting putrescine synthesis changes nitrogen metabolism and promotes putrescine recycling. In fact, putrescine is believed to be easily recycled via diamine oxidase to GABA (Shelp et al., 2012) and 
importantly, putrescine oxidation can be a source of ROS (see above), signaling a stress response and leading to changes in gene expression (Minocha et al., 2014; Gupta et al., 2016). Putrescine can thus be occasionally detrimental in terms of oxidative stress or net photosynthesis (Mohapatra et al., 2009; Pál et al., 2018). Whenever the pro-oxidant effect predominates over the anti-oxidant function of putrescine, the suppression of arginine formation and ADC activity (along with a decrease in putrescine and concomitant decrease of ROS production) may be beneficiary for plant performance under stress (for example, the decrease in putrescine synthesis by metasilicic acid $\left(\mathrm{H}_{2} \mathrm{SiO}_{3}\right)$ application can alleviate some effects of $\mathrm{K}^{+}$deficiency (Chen et al., 2016)). However, such a situation nevertheless seems unlikely under $\mathrm{K}^{+}$deficiency since putrescine accumulates to very high levels, certainly reflecting an adaptive trait of plant metabolism.

\section{Conclusions and perspectives}

Putrescine has specific biochemical properties that differ from other polyamines and this probably explains why $\mathrm{K}^{+}$deficiency appears to be closely associated with putrescine rather than spermine or spermidine. Putrescine accumulation under $\mathrm{K}^{+}$deficiency is perhaps advantageous via its concerted action on several cellular processes including cation balance, ultimately down-regulating MPT. To better understand stress responses where putrescine is involved, a difference should be made between endogenous, natural putrescine production under $\mathrm{K}^{+}$deficiency and artificial putrescine provision. To definitely appreciate the adaptive role of putrescine under $\mathrm{K}^{+}$deficiency, it will be necessary to use plant lines with altered putrescine content such as $A D C$ overexpression or knock-out lines and at the same time, verify putrescine subcellular distribution, measure both $\mathrm{K}^{+}$and $\mathrm{Ca}^{2+}$ content, and monitor mitochondrial activity (ATP synthesis, transmembrane potential, ROS production). Also, a possible venue would be to examine further the roles of putrescine in chloroplasts (its major site of production via the ADC pathway) and in particular, to check its effect on ion and $\mathrm{pH}$ homeostasis, electrochemical gradient across the thylakoid membrane, and ultimately optimization of photosynthesis. It should be kept in mind that aside from examples of positive effects of $A D C$ overexpression (increase in tolerance to drought, cold, or salinity in Arabidopsis, or rice (Alcázar et al., 2010; Wang et al., 2011)), toxic effects of putrescine over-production have been observed (see above). It is possible that deleterious effects were caused by enhanced DAO activity and excessive ROS production. Therefore, one might hypothesize that engineering plants with simultaneous overexpression of ADC and knockdown of DAO could be beneficial. In the field, the putrescine content in crops could be used as a component of the metabolomics signature of $\mathrm{K}^{+}$nutrition or a marker to detect $\mathrm{K}^{+}$responsive varieties, because it reflects several processes (described above) triggered by intracellular $\mathrm{K}^{+}$scarcity. In the near future, it might then be amongst biomarkers used by precision agriculture.

\section{Acknowledgements}


G.T. thanks the financial support of the Région Pays de la Loire and Angers Loire Métropole via the Connect Talent grant Isoseed. J.C. was supported by an Australia Awards PhD Scholarship.

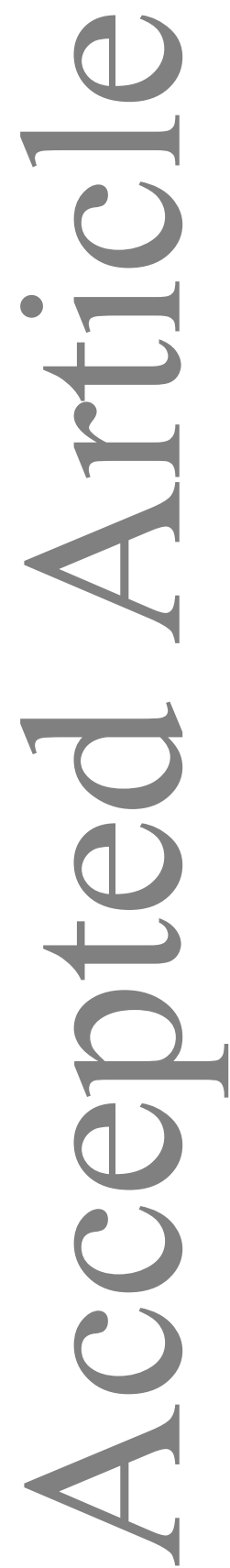




\section{References}

Adams DO, Franke KE, Christensen LP. 1990. Elevated putrescine levels in grapevine leaves that display symptoms of potassium deficiency. American Journal of Enology and Viticulture 41: 121-125.

Aguilar-Bryan L, Bryan J. 1999. Molecular biology of adenosine triphosphate-sensitive potassium channels. Endocrine Reviews 20: 101-135.

Alcázar R, Bitrián M, Bartels D, Koncz C, Altabella T, Tiburcio AF. 2011. Polyamine metabolic canalization in response to drought stress in Arabidopsis and the resurrection plant Craterostigma plantagineum. Plant Signaling and Behavior 6: 243250.

Alcázar R, García-Martínez JL, Cuevas JC, Tiburcio AF, Altabella T. 2005. Overexpression of ADC2 in Arabidopsis induces dwarfism and late-flowering through GA deficiency. The Plant Journal 43: 425-436.

Alcázar R, Marco F, Cuevas JC, Patron M, Ferrando A, Carrasco P, Tiburcio AF, Altabella T. 2006. Involvement of polyamines in plant response to abiotic stress. Biotechnology Letters 28: 1867-1876.

Alcázar R, Planas J, Saxena T, Zarza X, Bortolotti C, Cuevas J, Bitrián M, Tiburcio AF, Altabella T. 2010. Putrescine accumulation confers drought tolerance in transgenic Arabidopsis plants over-expressing the homologous Arginine decarboxylase 2 gene. Plant Physiology and Biochemistry 48: 547-552.

Alet AI, Sánchez DH, Cuevas JC, Marina M, Carrasco P, Altabella T, Tiburcio AF, Ruiz OA. 2012. New insights into the role of spermine in Arabidopsis thaliana under long-term salt stress. Plant Science 182: 94-100.

Alexandersson E, Jacobson D, Vivier MA, Weckwerth W, Andreasson E. 2014. Fieldomics - understanding large-scale molecular data from field crops. Frontiers in Plant Science 5: Article 286.

Armengaud P, Sulpice R, Miller AJ, Stitt M, Amtmann A, Gibon Y. 2009. Multilevel analysis of primary metabolism provides new insights into the role of potassium nutrition for glycolysis and nitrogen assimilation in Arabidopsis roots. Plant Physiology 150: 772-785.

Arpagaus S, Rawyler A, Braendle R. 2002. Occurrence and characteristics of the mitochondrial permeability transition in plants. Journal of Biological Chemistry 277: 1780-1787.

Aurisano N, Bertani A, Mattana M, Reggiani R. 1993. Abscisic acid induced stress-like polyamine pattern in wheat seedlings, and its reversal by potassium ions. Physiologia Plantarum 89: 687-692.

Aziz A, Martin-Tanguy J, Larher F. 1998. Stress-induced changes in polyamine and tyramine levels can regulate proline accumulation in tomato leaf discs treated with sodium chloride. Physiologia Plantarum 104: 195-202.

Bagni N, Ruiz-Carrasco K, Franceschetti M, Fornalè S, Fornasiero RB, Tassoni A. 2006. Polyamine metabolism and biosynthetic gene expression in Arabidopsis thaliana under salt stress. Plant Physiology and Biochemistry 44: 776-786.

Balestrasse KB, Gallego SM, Benavides MP, Tomaro ML. 2005. Polyamines and proline are affected by cadmium stress in nodules and roots of soybean plants. Plant and Soil 270: 343-353.

Basso LC, Smith TA. 1974. Effect of mineral deficiency on amine formation in higher plants. Phytochemistry 13: 875-883.

Basu R, Ghosh B. 1991. Polyamines in various rice (Oryza sativa) genotypes with respect to sodium chloride salinity. Physiologia Plantarum 82: 575-581. 
Basu R, Maitra N, Ghosh B. 1988. Salinity results in polyamine accumulation in early rice (Oryza sativa L.) seedlings. Functional Plant Biology 15: 777-786.

Battaglia V, Grancara S, Satriano J, Saccoccio S, Agostinelli E, Toninello A. 2010. Agmatine prevents the $\mathrm{Ca}^{2+}$-dependent induction of permeability transition in rat brain mitochondria. Amino Acids 38: 431-437.

Benavides MP, Aizencang G, Tomaro ML. 1997. Polyamines in Helianthus annuus L. during germination under salt stress. Journal of Plant Growth Regulation 16: 205-211.

Bennett EM, Ekstrom JL, Pegg AE, Ealick SE. 2002. Monomeric S-adenosylmethionine decarboxylase from plants provides an alternative to putrescine stimulation. Biochemistry 41: 14509-14517.

Borrell A, Culianez-Macia FA, Altabella T, Besford RT, Flores D, Tiburcio AF. 1995. Arginine decarboxylase is localized in chloroplasts. Plant Physiology 109: 771-776.

Bortolotti C, Cordeiro A, Alcázar R, Borrell A, Culiañez-Macià FA, Tiburcio AF, Altabella T. 2004. Localization of arginine decarboxylase in tobacco plants. Physiologia Plantarum 120: 84-92.

Brüggemann LI, Pottosin II, Schönknecht G. 1998. Cytoplasmic polyamines block the fast-activating vacuolar cation channel. The Plant Journal 16: 101-105.

Buch-Pedersen MJ, Rudashevskaya EL, Berner TS, Venema K, Palmgren MG. 2006. Potassium as an intrinsic uncoupler of the plasma membrane $\mathrm{H}^{+}$-ATPase. Journal of Biological Chemistry 281: 38285-38292.

Camacho-Cristóbal JJ, Maldonado JM, González-Fontes A. 2005. Boron deficiency increases putrescine levels in tobacco plants. Journal of plant physiology 162: 921928.

Capell T, Bassie L, Christou P. 2004. Modulation of the polyamine biosynthetic pathway in transgenic rice confers tolerance to drought stress. Proceedings of the National Academy of Sciences of the United States of America 101: 9909-9914.

Carta F, Temperini C, Innocenti A, Scozzafava A, Kaila K, Supuran CT. 2010. Polyamines inhibit carbonic anhydrases by anchoring to the zinc-coordinated water molecule. Journal of medicinal chemistry 53: 5511-5522.

Chen CT, Kao CH. 1993. Osmotic stress and water stress have opposite effects on putrescine and proline production in excised rice leaves. Plant Growth Regulation 13: 197-202.

Chen D, Cao B, Qi L, Yin L, Wang S, Deng X. 2016. Silicon-moderated K-deficiencyinduced leaf chlorosis by decreasing putrescine accumulation in sorghum. Annals of Botany 118: 305-315.

Chérel I, Lefoulon C, Boeglin M, Sentenac H. 2013. Molecular mechanisms involved in plant adaptation to low $\mathrm{K}^{+}$availability. Journal of Experimental Botany 65: 833-848.

Coleman R, Hegartv M. 1957. Metabolism of DL-ornithine-2- ${ }^{14} \mathrm{C}$ in normal and potassiumdeficient barley. Nature 179: 376-377.

Coleman R, Richards F. 1956. Physiological studies in plant nutrition: XVIII. Some aspects of nitrogen metabolism in barley and other plants in relation to potassium deficiency. Annals of Botany 20: 393-409.

Corey K, Barker A. 1989. Ethylene evolution and polyamine accumulation by tomato subjected to interactive stresses of ammonium toxicity and potassium deficiency. Journal of the American Society for Horticultural Science (USA) 114: 651-655.

Cowley T, Walters DR. 2005. Local and systemic changes in arginine decarboxylase activity, putrescine levels and putrescine catabolism in wounded oilseed rape. New Phytologist 165: 807-811.

Crocomo O, Basso L. 1974. Accumulation of putrescine and related amino acids in potassium deficient Sesamum. Phytochemistry 13: 2659-2665. 
Cuevas JC, López-Cobollo R, Alcázar R, Zarza X, Koncz C, Altabella T, Salinas J, Tiburcio AF, Ferrando A. 2008. Putrescine is involved in Arabidopsis freezing tolerance and cold acclimation by regulating abscisic acid levels in response to low temperature. Plant Physiology 148: 1094-1105.

Cui J, Abadie C, Carroll A, Lamade E, Tcherkez G. 2019a. Responses to K deficiency and waterlogging interact via respiratory and nitrogen metabolism. Plant Cell and Environment 42: 647-658.

Cui J, Davanture M, Zivy M, Lamade E, Tcherkez G. 2019b. Metabolic responses to potassium availability and waterlogging reshape respiration and carbon use efficiency in oil palm. New Phytologist 223: 310-322.

Dalla Via L, Di Noto V, Toninello A. 1999. Binding of spermidine and putrescine to energized liver mitochondria. Archives of biochemistry and biophysics 365: 231-238.

Davis GA, Rutherford AW, Kramer DM. 2017. Hacking the thylakoid proton motive force for improved photosynthesis: modulating ion flux rates that control proton motive force partitioning into $\Delta \psi$ and $\Delta \mathrm{pH}$. Philosophical Transactions of the Royal Society B: Biological Sciences 372: Article 20160381.

Diem B, Godbold D. 1993. Potassium, calcium and magnesium antagonism in clones of Populus trichocarpa. Plant and Soil 155: 411-414.

DiTomaso JM, Shaff JE, Kochian LV. 1989. Putrescine-induced wounding and its effects on membrane integrity and ion transport processes in roots of intact corn seedlings. Plant Physiology 90: 988-995.

Dobrovinskaya O, Muniz J, Pottosin I. 1999a. Inhibition of vacuolar ion channels by polyamines. The Journal of membrane biology 167: 127-140.

Dobrovinskaya O, Muñiz J, Pottosin II. 1999b. Asymmetric block of the plant vacuolar $\mathrm{Ca}^{2+}$-permeable channel by organic cations. European Biophysics Journal 28: 552563.

Erdei L, Trivedi S, Takeda K, Matsumoto H. 1990. Effects of osmotic and salt stresses on the accumulation of polyamines in leaf segments from wheat varieties differing in salt and drought tolerance. Journal of plant physiology 137: 165-168.

Escribano MI, Aguado P, Reguera RM, Merodio C. 1996. Conjugated polyamine levels and putrescine synthesis in cherimoya fruit during storage at different temperatures. Journal of plant physiology 147: 736-742.

Feirer RP, Hocking KL, Woods PJ. 1998. Involvement of arginine decarboxylase in the response of Arabidopsis thaliana to osmotic stress. Journal of plant physiology 153: 733-738.

Feng J, Barker AV. 1993. Polyamine concentration and ethylene evolution in tomato plants under nutritional stress. HortScience 28: 109-110.

Flores HE, Galston AW. 1982. Polyamines and plant stress: activation of putrescine biosynthesis by osmotic shock. Science 217: 1259-1261.

Flores HE, Galston AW. 1984. Osmotic stress-induced polyamine accumulation in cereal leaves. Plant Physiology 75: 102-109.

Fortes F, Castilho RF, Catisti R, Carnieri EGS, Vercesi AE. 2001. Ca2+ induces a cyclosporin A-insensitive permeability transition pore in isolated potato tuber mitochondria mediated by reactive oxygen species. Journal of Bioenergetics and Biomembranes 33: 43-51.

Foster SA, Walters DR. 1991. Polyamine concentrations and arginine decarboxylase activity in wheat exposed to osmotic stress. Physiologia Plantarum 82: 185-190.

Friedman Ra, Altman A, Levin N. 1989. The effect of salt stress on polyamine biosynthesis and content in mung bean plants and in halophytes. Physiologia Plantarum 76: 295302. 
Friedman RA, Levin N, Altman A. 1986. Presence and identification of polyamines in xylem and phloem exudates of plants. Plant Physiology 82: 1154-1157.

Fujita M, Shinozaki K 2015. Polyamine transport systems in plants. In: Kusano T, Suzuki H eds. Polyamines. Tokyo: Springer, 179-185.

Galston AW, Sawhney RK. 1990. Polyamines in plant physiology. Plant Physiology 94: 406-410.

Gilliham M, Athman A, Tyerman S, Conn S. 2011. Cell-specific compartmentation of mineral nutrients is an essential mechanism for optimal plant productivity - another role for TPC1? Plant Signaling and Behavior 6: 16656-11661.

Groppa MD, Ianuzzo MP, Tomaro ML, Benavides MP. 2007. Polyamine metabolism in sunflower plants under long-term cadmium or copper stress. Amino Acids 32: 265-275.

Gupta K, Sengupta A, Chakraborty M, Gupta B. 2016. Hydrogen peroxide and polyamines act as double edged swords in plant abiotic stress responses. Frontiers in Plant Science 7: Article 01343.

Hamamoto S, Marui J, Matsuoka K, Higashi K, Igarashi K, Nakagawa T, Kuroda T, Mori Y, Murata Y, Nakanishi Y. 2008. Characterization of a tobacco TPK-type K+ channel as a novel tonoplast $\mathrm{K}^{+}$channel using yeast tonoplasts. Journal of Biological Chemistry 283: 1911-1920.

Hanfrey C, Sommer S, Mayer MJ, Burtin D, Michael AJ. 2001. Arabidopsis polyamine biosynthesis: absence of ornithine decarboxylase and the mechanism of arginine decarboxylase activity. The Plant Journal 27: 551-560.

Hauschild MZ. 1993. Putrescine (1,4-diaminobutane) as an indicator of pollution-induced stress in higher plants: barley and rape stressed with $\mathrm{Cr}(\mathrm{III})$ or $\mathrm{Cr}(\mathrm{VI})$. Ecotoxicology and Environmental Safety 26: 228-247.

Houdusse F, Garnica M, Zamarreño AM, Yvin JC, García-Mina J. 2008. Possible mechanism of the nitrate action regulating free-putrescine accumulation in ammonium fed plants. Plant Science 175: 731-739.

Houman F, Godbold DL, Majcherczyk A, Shasheng W, Hüttermann A. 1991. Polyamines in leaves and roots of Populus maximowiczii grown in differing levels of potassium and phosphorus. Canadian journal of forest research 21: 1748-1751.

Hoyos ME, Palmieri L, Wertin T, Arrigoni R, Polacco JC, Palmieri F. 2003. Identification of a mitochondrial transporter for basic amino acids in Arabidopsis thaliana by functional reconstitution into liposomes and complementation in yeast. The Plant Journal 33: 1027-1035.

Igarashi K, Kashiwagi K, Kobayashi H, Ohnishi R, Kakegawa T, Nagasu A, Hirose S. 1989. Effect of polyamines on mitochondrial $F_{1}$-ATPase catalyzed reactions. The Journal of Biochemistry 106: 294-298.

Ioannidis NE, Cruz JA, Kotzabasis K, Kramer DM. 2012. Evidence that putrescine modulates the higher plant photosynthetic proton circuit. PLOS ONE 7: e29864.

Ioannidis NE, Kotzabasis K. 2007. Effects of polyamines on the functionality of photosynthetic membrane in vivo and in vitro. Biochimica et Biophysica Acta (BBA)Bioenergetics 1767: 1372-1382.

Ioannidis NE, Sfichi L, Kotzabasis K. 2006. Putrescine stimulates chemiosmotic ATP synthesis. Biochimica et Biophysica Acta (BBA)-Bioenergetics 1757: 821-828.

Jakobsen ST. 1993. Interaction between plant nutrients: III. antagonism between potassium, magnesium and calcium. Acta Agriculturae Scandinavica, Section B - Soil \& Plant Science 43: 1-5.

Janicka-Russak M, KabaŁa K, MŁodzińska E, KŁobus G. 2010. The role of polyamines in the regulation of the plasma membrane and the tonoplast proton pumps under salt stress. Journal of plant physiology 167: 261-269. 
Katiyar S, Dubey R. 1990. Changes in polyamine titer in rice seedlings following $\mathrm{NaCl}$ salinity stress. Journal of Agronomy and Crop Science 165: 19-27.

Klein H, Priebe A, Jäger H-J. 1979. Putrescine and spermidine in peas: effects of nitrogen source and potassium supply. Physiologia Plantarum 45: 497-499.

Knobloch KH, Berlin J. 1981. Phosphate mediated regulation of cinnamoyl putrescine biosynthesis in cell suspension cultures of Nicotiana tabacum. Planta Medica 42: 167172.

Kotakis C, Theodoropoulou E, Tassis K, Oustamanolakis C, Ioannidis NE, Kotzabasis K. 2014. Putrescine, a fast-acting switch for tolerance against osmotic stress. Journal of plant physiology 171: 48-51.

Krämer R, Mayr U, Heberger C, Tsompanidou S. 1986. Activation of the ADP/ATP carrier from mitochondria by cationic effectors. Biochimica et Biophysica Acta (BBA)Biomembranes 855: 201-210.

Krueger S, Giavalisco P, Krall L, Steinhauser M-C, Büssis D, Usadel B, Flügge U-I, Fernie AR, Willmitzer L, Steinhauser D. 2011. A topological map of the compartmentalized Arabidopsis thaliana leaf metabolome. PLOS ONE 6: Article e17806.

Lee T-M, Shieh Y-J, Chou C-H. 1996. Role of putrescine in enhancing shoot elongation in Scirpus mucronatus under submergence. Physiologia Plantarum 96: 419-424.

Lin C, Kao CH. 1999. Excess copper induces an accumulation of putrescine in rice leaves. Botanical Bulletin Academia Sinica 40: 213-218.

Lin CC, Kao CH. 2002. NaCl-induced changes in putrescine content and diamine oxidase activity in roots of rice seedlings. Biologia Plantarum 45: 633-636.

Lin J, Wang Y, Wang G. 2005. Salt stress-induced programmed cell death via $\mathrm{Ca}^{2+}$ mediated mitochondrial permeability transition in tobacco protoplasts. Plant Growth Regulation 45: 243-250.

Liu J, Zhang Y-y. 2004. Relationship between ATPase activity and conjugated polyamines in mitochondrial membrane from wheat seedling roots under osmotic stress. Journal of Environmental Sciences 16: 712-716.

Liu K, Fu H, Bei Q, Luan S. 2000. Inward potassium channel in guard cells as a target for polyamine regulation of stomatal movements. Plant Physiology 124: 1315-1326.

Lothier J, De Paepe R, Tcherkez G. 2019. Mitochondrial complex I dysfunction increases $\mathrm{CO}_{2}$ efflux and reconfigures metabolic fluxes of day respiration in tobacco leaves. New Phytologist 221: 750-763.

Masgrau C, Altabella T, Farrás R, Flores D, Thompson AJ, Besford RT, Tiburcio AF. 1997. Inducible overexpression of oat arginine decarboxylase in transgenic tobacco plants. The Plant Journal 11: 465-473.

McDonald RE, Kushad MM. 1986. Accumulation of putrescine during chilling injury of fruits. Plant Physiology 82: 324-326.

Meyer RC, Steinfath M, Lisec J, Becher M, Witucka-Wall H, Törjék O, Fiehn O, Eckardt $\ddot{A}$, Willmitzer L, Selbig J, et al. 2007. The metabolic signature related to high plant growth rate in Arabidopsis thaliana. Proceedings of the National Academy of Sciences 104: 4759-4764.

Minocha R, Majumdar R, Minocha SC. 2014. Polyamines and abiotic stress in plants: a complex relationship. Frontiers in Plant Science 5: Article 00175.

Mohapatra S, Minocha R, Long S, Minocha SC. 2009. Putrescine overproduction negatively impacts the oxidative state of poplar cells in culture. Plant Physiology and Biochemistry 47: 262-271.

Moschou PN, Paschalidis KA, Roubelakis-Angelakis KA. 2008. Plant polyamine catabolism: the state of the art. Plant Signaling and Behavior 3: 1061-1066. 
Murty KS, Smith TA, Bould C. 1971. The relation between the putrescine content and potassium status of black currant leaves. Annals of Botany 35: 687-695.

Mutlu F, Bozcuk S. 2007. Relationship between salt stress and levels of free and bound polyamines in sunflower plants. Plant Biosystems 141: 31-39.

Naka Y, Watanabe K, Sagor G, Niitsu M, Pillai MA, Kusano T, Takahashi Y. 2010. Quantitative analysis of plant polyamines including thermospermine during growth and salinity stress. Plant Physiology and Biochemistry 48: 527-533.

Ndayiragije A, Lutts S. 2006. Do exogenous polyamines have an impact on the response of a salt-sensitive rice cultivar to $\mathrm{NaCl}$ ? Journal of plant physiology 163: 506-516.

Öztürk L, Demir Y. 2003. Effects of putrescine and ethephon on some oxidative stress enzyme activities and proline content in salt stressed spinach leaves. Plant Growth Regulation 40: 89-95.

Pál M, Tajti J, Szalai G, Peeva V, Végh B, Janda T. 2018. Interaction of polyamines, abscisic acid and proline under osmotic stress in the leaves of wheat plants. Scientific Reports 8: Article 12839.

Palmieri L, Todd CD, Arrigoni R, Hoyos ME, Santoro A, Polacco JC, Palmieri F. 2006. Arabidopsis mitochondria have two basic amino acid transporters with partially overlapping specificities and differential expression in seedling development. Biochimica et Biophysica Acta (BBA) - Bioenergetics 1757: 1277-1283.

Pandolfi C, Pottosin I, Cuin T, Mancuso S, Shabala S. 2010. Specificity of polyamine effects on $\mathrm{NaCl}$-induced ion flux kinetics and salt stress amelioration in plants. Plant and Cell Physiology 51: 422-434.

Pastore D, Stoppelli MC, Di Fonzo N, Passarella S. 1999. The existence of the $\mathrm{K}^{+}$channel in plant mitochondria. Journal of Biological Chemistry 274: 26683-26690.

Peter HW, Pinheiro MR, Lima MS. 1981. Regulation of the F1-ATPase from mitochondria of Vigna sinensis (L.) Savi cv. Pitiuba by spermine, spermidine, putrescine, $\mathrm{Mg}^{2+}$, $\mathrm{Na}^{+}$, and $\mathrm{K}^{+}$. Canadian journal of biochemistry 59: 60-66.

Peuke AD, Jeschke WD, Hartung W. 2002. Flows of elements, ions and abscisic acid in Ricinus communis and site of nitrate reduction under potassium limitation. Journal of Experimental Botany 53: 241-250.

Phelps DC, McDonald RE. 1990. Inhibition of electron transport activities in mitochondria from avocado and pepper fruit by naturally occurring polyamines. Physiologia Plantarum 78: 15-21.

Pistocchi R, Antognoni F, Bagni N, Zannoni D. 1990. Spermidine uptake by mitochondria of Helianthus tuberosus. Plant Physiology 92: 690-695.

Pottosin I 2015. Polyamine action on plant ion channels and pumps. In: Kusano T, Suzuki H eds. Polyamines. Tokyo: Springer, 229-241.

Pottosin I, Schönknecht G. 1996. Ion channel permeable for divalent and monovalent cations in native spinach thylakoid membranes. The Journal of membrane biology 152: 223-233.

Pottosin I, Schönknecht G. 2007. Vacuolar calcium channels. Journal of Experimental Botany 58: 1559-1569.

Pottosin I, Velarde-Buendía AM, Bose J, Fuglsang AT, Shabala S. 2014a. Polyamines cause plasma membrane depolarization, activate $\mathrm{Ca}^{2+}$, and modulate $\mathrm{H}^{+}$-ATPase pump activity in pea roots. Journal of Experimental Botany 65: 2463-2472.

Pottosin I, Velarde-Buendía AM, Bose J, Zepeda-Jazo I, Shabala S, Dobrovinskaya O. 2014b. Cross-talk between reactive oxygen species and polyamines in regulation of ion transport across the plasma membrane: implications for plant adaptive responses. Journal of Experimental Botany 65: 1271-1283. 
Priebe A, Jäger HJ. 1978. Effect of $\mathrm{NaCl}$ on the levels of putrescine and related polyamines in plants differing in salt tolerance. Plant Science Letters 12: 365-369.

Reggiani R, Aurisano N, Mattana M, Bertani A. 1993. Influence of $\mathrm{K}^{+}$ions on polyamine level in wheat seedlings. Journal of plant physiology 141: 136-140.

Reggiani R, Giussani P, Bertani A. 1990. Relationship between the accumulation of putrescine and the tolerance to oxygen-deficit stress in Gramineae seedlings. Plant and Cell Physiology 31: 489-494.

Reggiani R, Hochkoeppler A, Bertani A. 1989. Polyamines in rice seedlings under oxygendeficit stress. Plant Physiology 91: 1197-1201.

Reggiani R, Zaina S, Bertani A. 1992. Plasmalemma ATPase in rice coleoptiles; Stimulation by putrescine and polyamines. Phytochemistry 31: 417-419.

Richards F, Coleman R. 1952. Occurrence of putrescine in potassium-deficient barley. Nature 170: 460-462.

Rugolo M, Antognoni F, Flamigni A, Zannoni D. 1991. Effects of polyamines on the oxidation of exogenous NADH by Jerusalem artichoke (Helianthus tuberosus) mitochondria. Plant Physiology 95: 157-163.

Ruhl E. 1989. Effect of potassium and nitrogen supply on the distribution of minerals and organic acids and the composition of grape juice of Sultana vines. Australian Journal of Experimental Agriculture 29: 133-137.

Sarjala T. 1996. Growth, potassium and polyamine concentrations of Scots pine seedlings in relation to potassium availability under controlled growth conditions. Journal of plant physiology 147: 593-598.

Sarjala T, Kaunisto S. 1993. Needle polyamine concentrations and potassium nutrition in Scots pine. Tree Physiology 13: 87-96.

Scaramagli S, Biondi S, Leone A, Grillo S, Torrigiani P. 2000. Acclimation to low water potential in potato cell suspension cultures leads to changes in putrescine metabolism. Plant Physiology and Biochemistry 38: 345-351.

Scott I, Logan DC. 2008. Mitochondrial morphology transition is an early indicator of subsequent cell death in Arabidopsis. New Phytologist 177: 90-101.

Shabala S. 2017. Signalling by potassium: another second messenger to add to the list? Journal of Experimental Botany 68: 4003-4007.

Shelp BJ, Bozzo GG, Trobacher CP, Zarei A, Deyman KL, Brikis CJ. 2012. Hypothesis/review: contribution of putrescine to 4-aminobutyrate (GABA) production in response to abiotic stress. Plant Science 193: 130-135.

Shih CY, Kao CH. 1996. Growth inhibition in suspension-cultured rice cells under phosphate deprivation is mediated through putrescine accumulation. Plant Physiology 111: $721-724$.

Sinclair C. 1969. The level and distribution of amines in barley as affected by potassium nutrition, arginine level, temperature fluctuation and mildew infection. Plant and Soil 30: 423-438.

Sjölin A, Møller I. 1991. The effect of polyamines and other cations on NADH oxidation on the inner surface of the inner mitochondrial membrane. Plant Physiology and Biochemistry 29: 607-613.

Slocum RD. 2005. Genes, enzymes and regulation of arginine biosynthesis in plants. Plant Physiology and Biochemistry 43: 729-745.

Smith GS, Lauren DR, Cornforth IS, Agnew MP. 1982. Evaluation of putrescine as a biochemical indicator of the potassium requirements of lucerne. New Phytologist 91: 419-428.

Smith T 1984. Putrescine and inorganic ions. In: Timmermann B, C S, Loewus F eds. Phytochemical adaptations to stress. Boston: Springer, 7-54. 
Smith TA, Richards FJ. 1962. The biosynthesis of putrescine in higher plants and its relation to potassium nutrition. The Biochemical journal 84: 292-294.

Stefanelli C, Maddalena Z, Bonavita F, Flamigni F, Zambonin L, Landi L, Pignatti C, Guarnieri C, Caldarera CM. 2000. Polyamines directly induce release of cytochrome c from heart mitochondria. Biochemical Journal 347: 875-880.

Su GX, Bai X. 2008. Contribution of putrescine degradation to proline accumulation in soybean leaves under salinity. Biologia Plantarum 52: 796-801.

Su N, Wu Q, Chen J, Shabala L, Mithöfer A, Wang H, Qu M, Yu M, Cui J, Shabala S. 2019. GABA operates upstream of $\mathrm{H}^{+}$-ATPase and improves salinity tolerance in Arabidopsis by enabling cytosolic $\mathrm{K}^{+}$retention and $\mathrm{Na}^{+}$exclusion. Journal of Experimental Botany 70: 6349-6361.

Sung H-I, Liu L-F, Kao CH. 1994. Putrescine accumulation is associated with growth inhibition in suspension-cultured rice cells under potassium deficiency. Plant and Cell Physiology 35: 313-316.

Sung J, Lee S, Lee Y, Ha S, Song B, Kim T, Waters BM, Krishnan HB. 2015. Metabolomic profiling from leaves and roots of tomato (Solanum lycopersicum L.) plants grown under nitrogen, phosphorus or potassium-deficient condition. Plant Science 241: 55-64.

Szabo I, Zoratti M. 2014. Mitochondrial channels: ion fluxes and more. Physiological reviews 94: 519-608.

Tabor CW. 1960. The stabilizing effect of spermine and related amines on mitochondria and protoplasts. Biochemical and Biophysical Research Communications 2: 117-120.

Tachimoto M, Fukutomi M, Matsushiro H, Kobayashi M, Takahashi E. 1992. Role of putrescine in Lemna plants under potassium deficiency. Soil Science and Plant Nutrition 38: 307-313.

Takahashi H, Imamura T, Miyagi A, Uchimiya H. 2012. Comparative metabolomics of developmental alterations caused by mineral deficiency during in vitro culture of Gentiana triflora. Metabolomics 8: 154-163.

Takusagawa F, Kamitori S, Markham GD. 1996. Structure and function of Sadenosylmethionine synthetase: crystal structures of S-adenosylmethionine synthetase with ADP, BrADP, and PPi at 2.8 A resolution. Biochemistry 35: 2586-2596.

Tamai T, Shimada Y, Sugimoto T, Shiraishi N, Oji Y. 2000. Potassium stimulates the efflux of putrescine in roots of barley seedlings. Journal of plant physiology 157: 619626.

Tassoni A, Franceschetti M, Bagni N. 2008. Polyamines and salt stress response and tolerance in Arabidopsis thaliana flowers. Plant Physiology and Biochemistry 46: 607-613.

Tattini M, Heimler D, Traversi ML, Pieroni A. 1993. Polyamine analysis in salt stressed plants of olive (Olea europaea L.). Journal of Horticultural Science 68: 613-617.

Tiburcio AF, Altabella T, Bitrián M, Alcázar R. 2014. The roles of polyamines during the lifespan of plants: from development to stress. Planta 240: 1-18.

Tiwari BS, Belenghi B, Levine A. 2002. Oxidative stress increased respiration and generation of reactive oxygen species, resulting in ATP depletion, opening of mitochondrial permeability transition, and programmed cell death. Plant Physiology 128: 1271-1281.

Toninello A, Dalla Via L, Siliprandi D, Garlid KD. 1992. Evidence that spermine, spermidine, and putrescine are transported electrophoretically in mitochondria by a specific polyamine uniporter. Journal of Biological Chemistry 267: 18393-18397. 
Toninello A, Salvi M, Mondov B. 2004. Interaction of biologically active amines with mitochondria and their roles in the mitochondrial mediated pathway of apoptosis. Current Medicinal Chemistry 11: 2349-2374.

Trono D, Laus MN, Soccio M, Alfarano M, Pastore D. 2015. Modulation of potassium channel activity in the balance of ROS and ATP Production by durum wheat mitochondria - an amazing defense tool against hyperosmotic stress. Frontiers in Plant Science 6: Article 1072.

Turner LB, Steward GR. 1986. The effect of water stress upon polyamine levels in barley (Hordeum vulgare L.) leaves. Journal of Experimental Botany 37: 170-177.

Turner LB, Stewart GR. 1988. Factors affecting polyamine accumulation in barley (Hordeum vulgare L.) leaf sections during osmotic stress. Journal of Experimental Botany 39: 311-316.

Urano K, Yoshiba Y, Nanjo T, Ito T, Yamaguchi-Shinozaki K, Shinozaki K. 2004. Arabidopsis stress-inducible gene for arginine decarboxylase AtADC2 is required for accumulation of putrescine in salt tolerance. Biochemical and Biophysical Research Communications 313: 369-375.

Velarde-Buendía AM, Shabala S, Cvikrova M, Dobrovinskaya O, Pottosin I. 2012. Saltsensitive and salt-tolerant barley varieties differ in the extent of potentiation of the ROS-induced $\mathrm{K}^{+}$efflux by polyamines. Plant Physiology and Biochemistry 61: 18-23.

Verma S, Mishra SN. 2005. Putrescine alleviation of growth in salt stressed Brassica juncea by inducing antioxidative defense system. Journal of plant physiology 162: 669-677.

Votyakova TV, Bazhenova EN, Zvjagilskaya RA. 1993. Yeast mitochondrial calcium uptake: regulation by polyamines and magnesium ions. Journal of Bioenergetics and Biomembranes 25: 569-574.

Votyakova TV, Wallace H, Dunbar B, Wilson SB. 1999. The covalent attachment of polyamines to proteins in plant mitochondria. European Journal of Biochemistry 260: 250-257.

Walker DJ, Leigh RA, Miller AJ. 1996. Potassium homeostasis in vacuolate plant cells. Proceedings of the National Academy of Sciences 93: 10510-10514.

Wang B-Q, Zhang Q-F, Liu J-H, Li G-H. 2011. Overexpression of PtADC confers enhanced dehydration and drought tolerance in transgenic tobacco and tomato: effect on ROS elimination. Biochemical and Biophysical Research Communications 413: $10-16$.

Wang CY. 1987. Changes of polyamines and ethylene in cucumber seedlings in response to chilling stress. Physiologia Plantarum 69: 253-257.

Wang J-W, Kao CH. 2006. Aluminum-inhibited root growth of rice seedlings is mediated through putrescine accumulation. Plant and Soil 288: 373-381.

Wang Y, Wu W-H. 2013. Potassium transport and signaling in higher plants. Annual review of plant biology 64: 451-476.

Wang Z, Wang Y, Shi J, Zheng Q, Gao L, Wang Q, Zuo J. 2019. Effects of putrescine on the postharvest physiology characteristics in cowpea. Food Science and Nutrition 7: 395-403.

Watson MB, Emory KK, Piatak RM, Malmberg RL. 1998. Arginine decarboxylase (polyamine synthesis) mutants of Arabidopsis thaliana exhibit altered root growth. The Plant Journal 13: 231-239.

Watson MB, Malmberg RL. 1996. Regulation of Arabidopsis thaliana (L.) Heynh arginine decarboxylase by potassium deficiency stress. Plant Physiology 111: 1077-1083.

Weinstein LH, Kaur-Sawhney R, Rajam MV, Wettlaufer SH, Galston AW. 1986. Cadmium-induced accumulation of putrescine in oat and bean leaves. Plant Physiology 82: 641-645. 
Yoshida D. 1969. Formation of putrescine from ornithine and arginine in tobacco plants. Plant and Cell Physiology 10: 393-397.

Young ND, Galston AW. 1983. Putrescine and acid stress: induction of arginine decarboxylase activity and putrescine accumulation by low $\mathrm{pH}$. Plant Physiology 71: 767-771.

Young ND, Galston AW. 1984. Physiological control of arginine decarboxylase activity in K-deficient oat shoots. Plant Physiology 76: 331-335.

Yoza K-I, Takeda Y, Sekiya K, Nogata Y, Ohta H. 1996. Putrescine accumulation in wounded green banana fruit. Phytochemistry 42: 331-334.

Zaidan HA, Broetto F, de Oliveira ET, Gallo LA, Crocomo OJ. 1999. Influence of potassium nutrition and the nitrate/ammonium ratio on the putrescine and spermidine contents in banana vitroplants. Journal of plant nutrition 22: 1123-1140.

Zapata PJ, Serrano Ma, Pretel MT, Amorós A, Botella MÁ. 2004. Polyamines and ethylene changes during germination of different plant species under salinity. Plant Science 167: 781-788.

Zepeda-Jazo I, Velarde-Buendía AM, Enríquez-Figueroa R, Bose J, Shabala S, MuñizMurguía J, Pottosin II. 2011. Polyamines interact with hydroxyl radicals in activating $\mathrm{Ca}^{2+}$ and $\mathrm{K}^{+}$transport across the root epidermal plasma membranes. Plant Physiology 157: 2167-2180.

Zhang G-w, Xu S-c, Hu Q-z, Mao W-h, Gong Y-m. 2014. Putrescine plays a positive role in salt-tolerance mechanisms by reducing oxidative damage in roots of vegetable soybean. Journal of Integrative Agriculture 13: 349-357.

Zhao F, Song C-P, He J, Zhu H. 2007. Polyamines improve $\mathrm{K}^{+} / \mathrm{Na}^{+}$homeostasis in barley seedlings by regulating root ion channel activities. Plant Physiology 145: 1061-1072.

Zhong M, Yuan Y, Shu S, Sun J, Guo S, Yuan R, Tang Y. 2016. Effects of exogenous putrescine on glycolysis and Krebs cycle metabolism in cucumber leaves subjected to salt stress. Plant Growth Regulation 79: 319-330.

Zorov DB, Juhaszova M, Sollott SJ. 2014. Mitochondrial reactive oxygen species (ROS) and ROS-induced ROS release. Physiological reviews 94: 909-950. 
Table 1. Summary and list of abiotic stress situations where putrescine quantity varies in plants. When putrescine decreases or does not change rather than increase, it is mentioned in italics. When the reference cited also include mutants, data tabulated here only refer to wild-type plants.

\section{Tabulated summary:}

Stress

Do other polyamine accumulate?

Change in putrescine content

K deficiency No in most cases

Osmotic shock Variable

Drought

No, except in drought-tolerant plants?

$\times 3$ to $\times 150$

$\times 2$ to $\times 14$

$\approx \times 2$

Salinity $(\mathrm{NaCl})$

Yes in most cases

Generally decreases

Other stresses Generally yes if mineral nutrition also impacted (heavy metals, N, etc.) $\times 2$ to $\times 10$

\section{Full table (with references):}

\section{Stress}

\section{K deficienc}

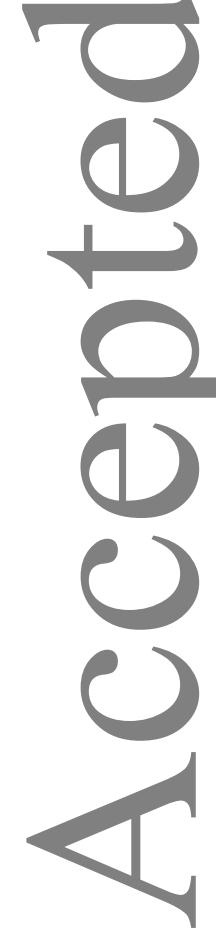

\begin{tabular}{|l|l|l|l|}
\hline Species and tissue & $\begin{array}{l}\text { Do other polyamines } \\
\text { accumulate? }\end{array}$ & $\begin{array}{l}\text { Observed fold change in } \\
\text { putrescine }\end{array}$ & Reference \\
\hline Various & Unknown & $\begin{array}{l}\text { Unknown (based on colorimetric } \\
\text { assays at that time) }\end{array}$ & $\begin{array}{l}\text { (Richards \& Coleman, 1952; Coleman \& } \\
\text { Richards, 1956; Smith \& Richards, 1962) }\end{array}$ \\
\hline Various & No (except in radish) & Up to 8 & (Basso \& Smith, 1974) \\
\hline Arabidopsis & No & 5 & (Watson \& Malmberg, 1996) \\
\hline Pea & Yes (spermidine, slightly) & $\begin{array}{l}\text { Up to 27 (depending on } \text { NH }_{4}{ }^{+} \\
\text {nutrition) }\end{array}$ & (Klein et al., 1979) \\
\hline $\begin{array}{l}\text { Blackcurrant } \\
\text { leaves }\end{array}$ & Unknown & $\begin{array}{l}\text { Very high (undetectable at high } \\
\text { K) }\end{array}$ & (Murty et al., 1971) \\
\hline Tobacco leaves & Unknown & $\begin{array}{l}\text { Up to 11 (radioactivity upon } \\
\text { isotopic arginine feeding) }\end{array}$ & (Yoshida, 1969) \\
\hline Grapevine leaves & No & 5.5 & (Adams et al., 1990) \\
\hline Lucerne & Unknown & Up to 150 & (Smith et al., 1982) \\
\hline Scots pine needles & No & Up to 100 & (Sarjala \& Kaunisto, 1993) \\
\hline Lemna species & Unknown & $\approx 10$ or 100 (depends on species) & (Tachimoto et al., 1992) \\
\hline $\begin{array}{l}\text { Scots pine } \\
\text { seedlings }\end{array}$ & $\begin{array}{l}\text { No change (roots) or decline } \\
\text { (needles) }\end{array}$ & Up to 9 & (Sarjala, 1996) \\
\hline Tomato leaves & No & $5 ?$ & (Corey \& Barker, 1989) \\
\hline $\begin{array}{l}\text { Poplar roots and } \\
\text { leaves }\end{array}$ & No (spermine declines) & 25 (leaves), 80 (roots) & (Houman et al., 1991) \\
\hline
\end{tabular}




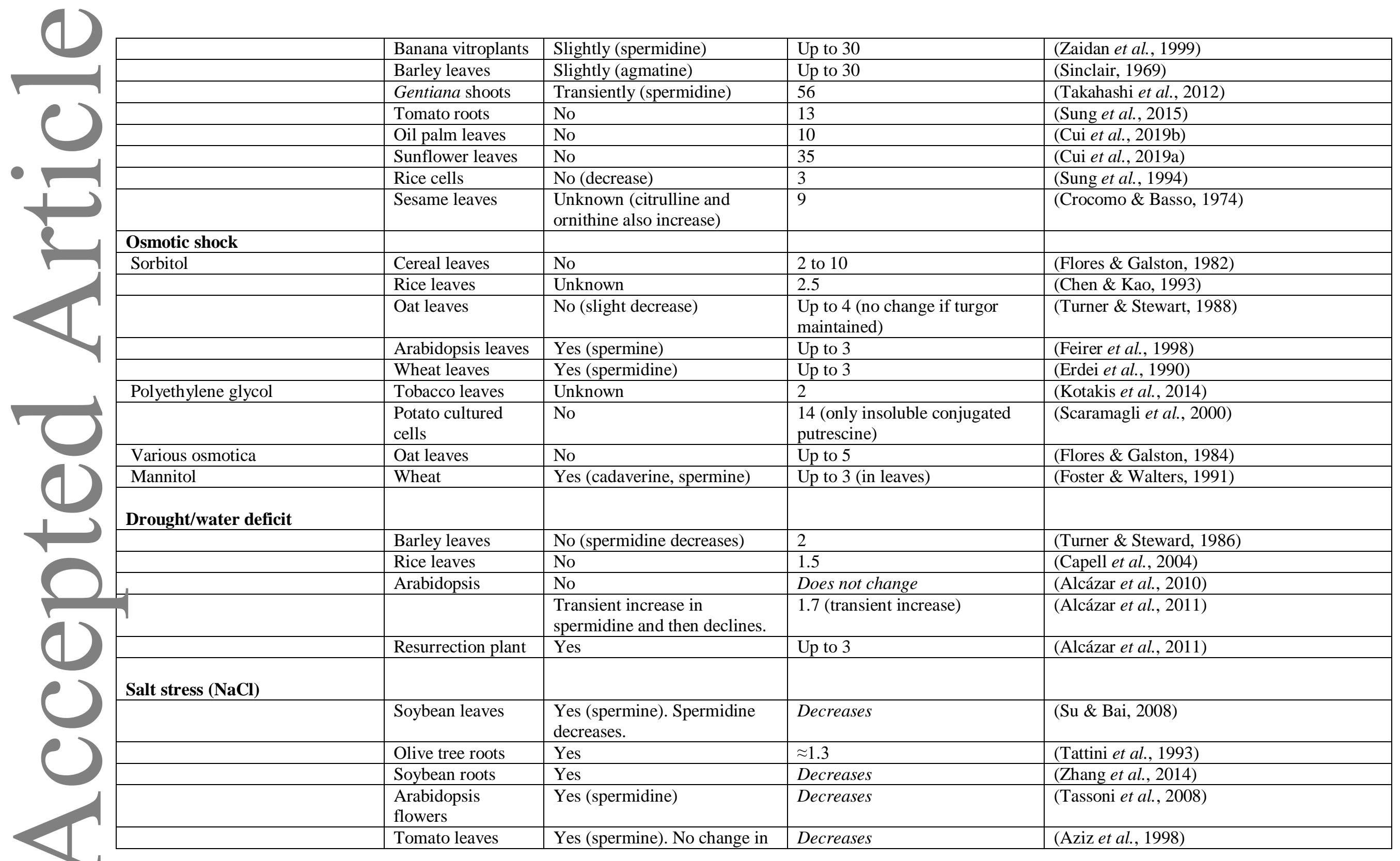

This article is protected by copyright. All rights reserved. 


\begin{tabular}{|c|c|c|c|c|}
\hline & & spermidine. & & \\
\hline & Rice seedling roots & Unknown & Decreases & (Lin \& Kao, 2002) \\
\hline & $\begin{array}{l}\text { Sunflower xylem } \\
\text { sap }\end{array}$ & Yes (spermidine) & Up to 2.5 & (Friedman et al., 1986) \\
\hline & Arabidopsis & Yes (both) & Does not change & (Alet et al., 2012) \\
\hline & Rice shoots & Variable & Up to 1.5 & (Katiyar \& Dubey, 1990) \\
\hline - & Various seedlings & Yes & Decreases & (Zapata et al., 2004) \\
\hline & $\begin{array}{l}\text { Sunflower } \\
\text { seedlings }\end{array}$ & No (decrease) & Decreases & (Benavides et al., 1997) \\
\hline & Arabidopsis & $\begin{array}{l}\text { Yes (spermidine). Spermine } \\
\text { decreases. }\end{array}$ & Decreases & (Bagni et al., 2006; Naka et al., 2010) \\
\hline & Rice seedlings & Yes & Up to 3.5 & (Basu \& Ghosh, 1991) \\
\hline & & $\begin{array}{l}\text { Yes (spermidine). Very small } \\
\text { change in spermine. }\end{array}$ & 2 & (Basu et al., 1988) \\
\hline & Sunflower shoots & $\begin{array}{l}\text { Yes (spermine). Spermidine } \\
\text { decreases. }\end{array}$ & $\begin{array}{l}\text { Decreases or does not change } \\
\text { (depends on variety) }\end{array}$ & (Mutlu \& Bozcuk, 2007) \\
\hline & Wheat leaves & Yes & Does not change & (Erdei et al., 1990) \\
\hline & Arabidopsis & $\begin{array}{l}\text { Yes (spermine). No change in } \\
\text { spermidine. }\end{array}$ & 2 & (Urano et al., 2004) \\
\hline & Various & No (decrease) & Decrease & (Priebe \& Jäger, 1978) \\
\hline & Mung bean & $\begin{array}{l}\text { Yes (spermidine). Spermine } \\
\text { content not measured. }\end{array}$ & Up to 4 (decrease in roots) & (Friedman et al., 1989) \\
\hline Other stresses & & & & \\
\hline Magnesium deficiency & Various & No (except in radish) & Up to 7.3 & (Basso \& Smith, 1974) \\
\hline $\begin{array}{l}\text { Phosphate deprivation (along } \\
\text { with } \mathrm{K}^{+} \text {) }\end{array}$ & Rice cells & No (decrease) & $\approx 2$ & (Shih \& Kao, 1996) \\
\hline Heavy metals: & & & & \\
\hline Aluminium $\left(\mathrm{Al}^{3+}\right)$ & Rice roots & No (tend to decline) & 3 & (Wang \& Kao, 2006) \\
\hline Cadmium $\left(\mathrm{Cd}^{2+}\right)$ & $\begin{array}{l}\text { Oat and bean } \\
\text { leaves }\end{array}$ & $\begin{array}{l}\text { Spermine increases, } \\
\text { spermidine does not change }\end{array}$ & Up to 10 & (Weinstein et al., 1986) \\
\hline & $\begin{array}{l}\text { Soybean nodules } \\
\text { and roots }\end{array}$ & Yes (spermine) & 2.5 (nodules), 1.5 (roots) & (Balestrasse et al., 2005) \\
\hline & Sunflower shoots & Yes & 2.7 & (Groppa et al., 2007) \\
\hline Chromium $\left(\mathrm{Cr}^{3+}, \mathrm{Cr}^{6+}\right)$ & $\begin{array}{l}\text { Barley and rape } \\
\text { seedlings }\end{array}$ & No & Up to 10 & (Hauschild, 1993) \\
\hline Copper $\left(\mathrm{Cu}^{2+}\right)$ & Rice leaves & Unknown & Up to 4 & (Lin \& Kao, 1999) \\
\hline & Sunflower shoots & Yes & 1.6 & (Groppa et al., 2007) \\
\hline
\end{tabular}

This article is protected by copyright. All rights reserved. 


\begin{tabular}{|c|c|c|c|c|c|}
\hline & Anoxia/hypoxia/submergence & Cereal seedlings & $\begin{array}{l}\text { Slightly (but numerical data } \\
\text { not reported) }\end{array}$ & Up to 2 & (Reggiani et al., 1990) \\
\hline \multirow{11}{*}{ - } & & Rice coleoptile & Slightly & 2 to 14 & (Reggiani et al., 1989; Reggiani et al., 1992) \\
\hline & & Scirpus shoots & No (decrease) & 6 & (Lee et al., 1996) \\
\hline & Cold & $\begin{array}{l}\text { Arabidopsis } \\
\text { seedlings }\end{array}$ & $\begin{array}{l}\text { Spermidine stays constant, } \\
\text { spermine decreases }\end{array}$ & Up to 5 & (Cuevas et al., 2008) \\
\hline & & Diverse fruits & Unknown, or decrease & Up to 2.5 & $\begin{array}{l}\text { (McDonald \& Kushad, 1986; Escribano et } \\
\text { al., 1996) }\end{array}$ \\
\hline & & $\begin{array}{l}\text { Cucumber } \\
\text { seedlings }\end{array}$ & Yes (spermidine) & Does not change & (Wang, 1987) \\
\hline & Boron deficiency & $\begin{array}{l}\text { Tobacco leaves } \\
\text { and roots }\end{array}$ & Yes & Up to 2 (leaves) and 5 (roots) & (Camacho-Cristóbal et al., 2005) \\
\hline & Change from nitrate to $\mathrm{NH}_{4}^{+}$ & Tomato & No & $\approx 3$ & (Feng \& Barker, 1993) \\
\hline & & $\begin{array}{l}\text { Pepper and wheat } \\
\text { leaves }\end{array}$ & Yes (pepper), No (wheat) & Up to 20 & (Houdusse et al., 2008) \\
\hline & Mechanical wounding & Rapeseed leaves & No & 2 & (Cowley \& Walters, 2005) \\
\hline & & Bananas & No & Up to 5 & (Yoza et al., 1996) \\
\hline & Low $\mathrm{pH}(<5)$ & Oat and pea leaves & Unknown & 2 to 8 & (Young \& Galston, 1983) \\
\hline
\end{tabular}


Figure legends :

Fig. 1. Simplified metabolic pathway of putrescine synthesis and utilization. (a) Chemical structure of putrescine. Note that it contains two $\mathrm{N}$ atoms and four $\mathrm{C}$ atoms, that all come from glutamate. (b) Pathways showing the direct route starting from glutamate via ornithine (black), putrescine synthesis via arginine (gray) and other polyamines synthesis (blue). Cofactors and other compounds involved in reactions are shown in green or light turquoise. The alternative use of $\mathrm{N}$-acetylornithine as an acetyl donor is shown in dashed green. The recycling of fumarate via the Krebs cycle and aspartate synthesis, and the recycling of ammonium by carbamoyl phosphate synthase are shown in dotted light turquoise. Abbreviations: 2OG, 2-oxoglutarate; ADC, arginine decarboxylase (chloroplastic); CP, carbamoyl phosphate; NAG, N-acetyl glutamate; NAGSA, N-acetyl glutamate semialdehyde; ODC, ornithine decarboxylase (cytosolic); P-NAG, phospho-N-acetyl glutamate; SAE, Sadenosyl methioninamine; SAM, S-adenosyl methionine; SMTA, S-methyl thioadenosine.

Fig. 2. Leaf cation balance under normal or low potassium availability in oil palm (a) and sunflower (b). In each panel, the inset shows the sum of cations, also in $\mu$ mol positive charges $\mathrm{g}^{-1} \mathrm{DW}$ (dry weight). Abbreviations: Min, other minor cations $\left(\mathrm{Zn}^{2+}, \mathrm{Cu}^{2+}, \mathrm{Mn}^{2+}\right.$, and $\mathrm{H}^{+}$ calculated assuming a $\mathrm{pH}$ value of 7); Put, putrescine (carrying two positive charges); Orn, ornithine (carrying one positive charge). From source data in Cui et al. (2019a, 2019b). Asterisks stand for a significant K-availability effect (in sunflower, there is a significant increase in putrescine although it remains very small in terms of positive charge load).

Fig. 3. Summary of possible roles of putrescine on cellular cation balance under $\mathbf{K}^{+}$ deficiency. Two main roles are highlighted here, via ions channels (orange, left) and $\mathrm{H}^{+}-$ ATPases (green, right). See main text for further details. Abbreviations: DAO, diamine oxidase; GABA, $\gamma$-aminobutyrate; ROS, reactive oxygen species.

Fig. 4. Summary of possible roles of putrescine on organelles under $\mathrm{K}^{+}$deficiency. Putrescine has a general positive effect on ATP synthesis in both mitochondria and chloroplasts via a number of mechanisms, including mitigation of mitochondrial permeability transition (MPT) and non-photochemical quenching (NPQ), respectively. Abbreviations: NDHs, NAD(P)H dehydrogenases; TCAP, tricarboxylic acid pathway. 
Jor

ACCOA

ATP

ave mome

mases

Glu Ior Acetate

SAE NAGSA

NADP $2 \mathrm{OG}$ COA ADP

or

ornithine. - - - - - - - - - - - - - - - - - -

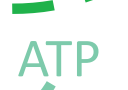

Arginosuccinate $\underset{A D P \text { Aspartate }}{\stackrel{1}{1} \text { Citrulline }}$

$\mathrm{NH}_{2}$

(i)

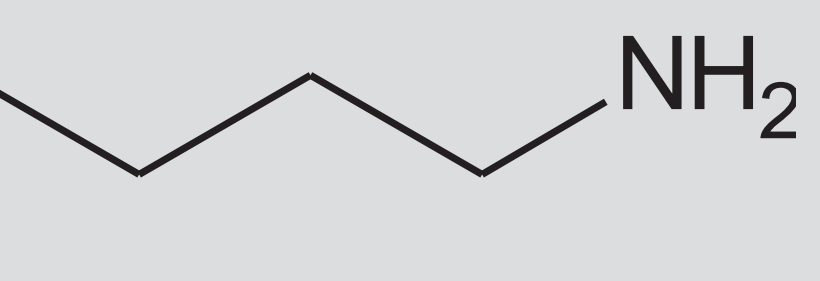

$\mathrm{CO}_{2} \underset{\mathrm{SAE}}{\mathrm{C}_{2}}$

Putrescine

$\mathrm{CO}_{2}$

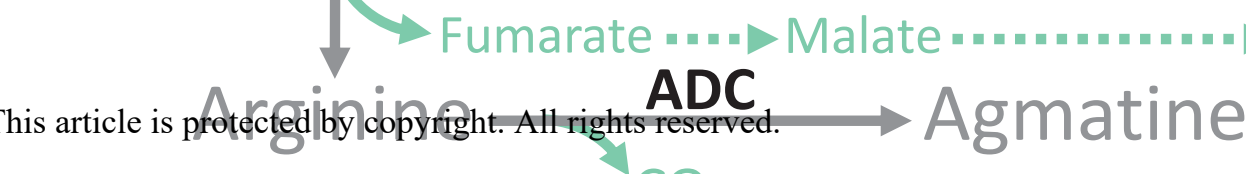

$\mathrm{CO}_{2}$

$\mathrm{N}$-carbamoyl putrescine OG 


\section{EFfECTS ON ION CHANNELS}

Inhibition of vacuolar channels

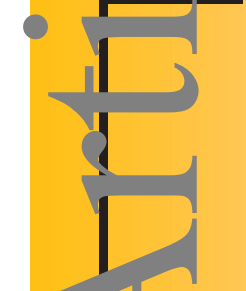

Action on $\mathrm{K}^{+}$channels

(inward, outward rectifiers) ?
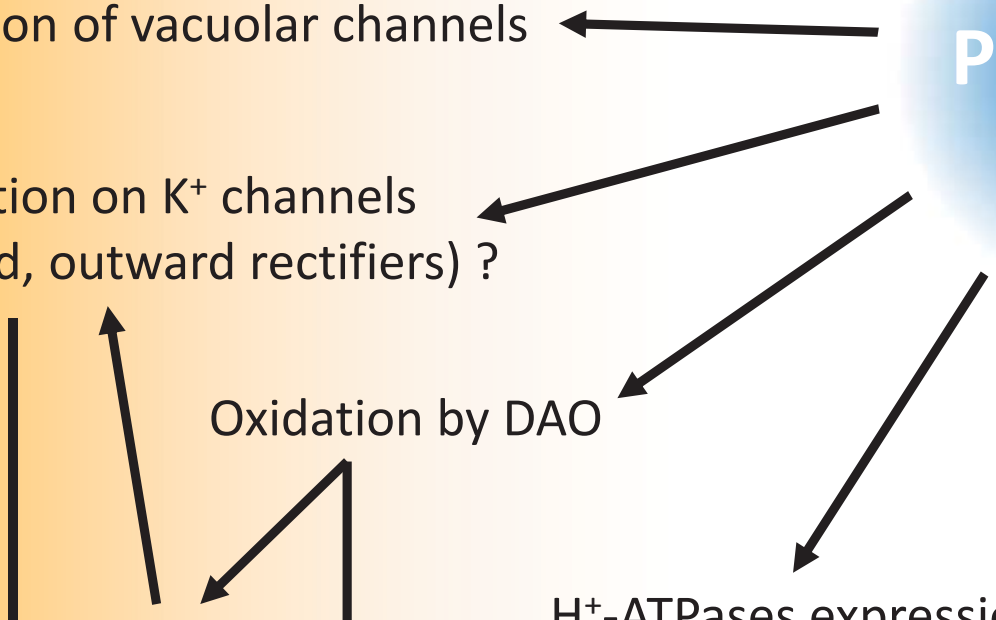

$\mathrm{H}^{+}$-ATPases expression ?

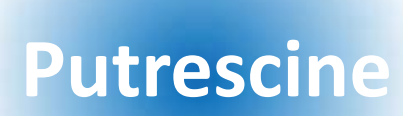

ROS

GABA

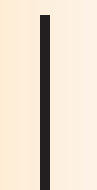

() Phosphorylation $\mathrm{H}^{+}$-ATPases

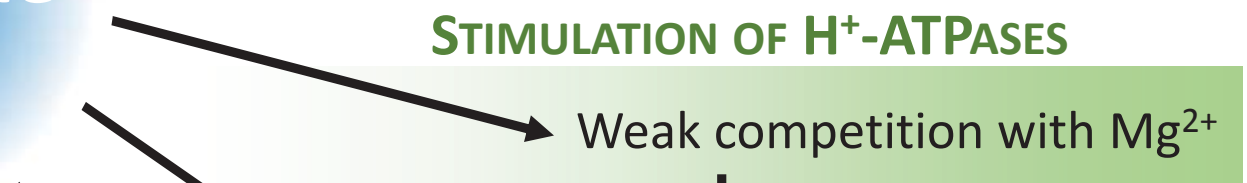

$\mathrm{Ca}^{2+}$-dependent kinases

$\downarrow$ 


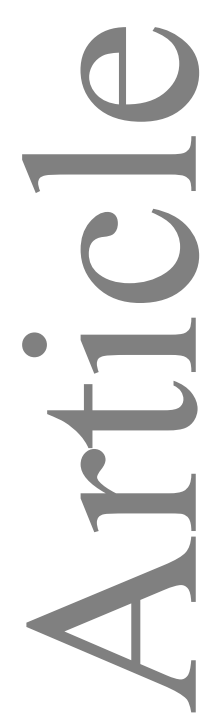

EFFECTS ON MITOCHONDRIAL METABOLISM

\section{Putrescine}
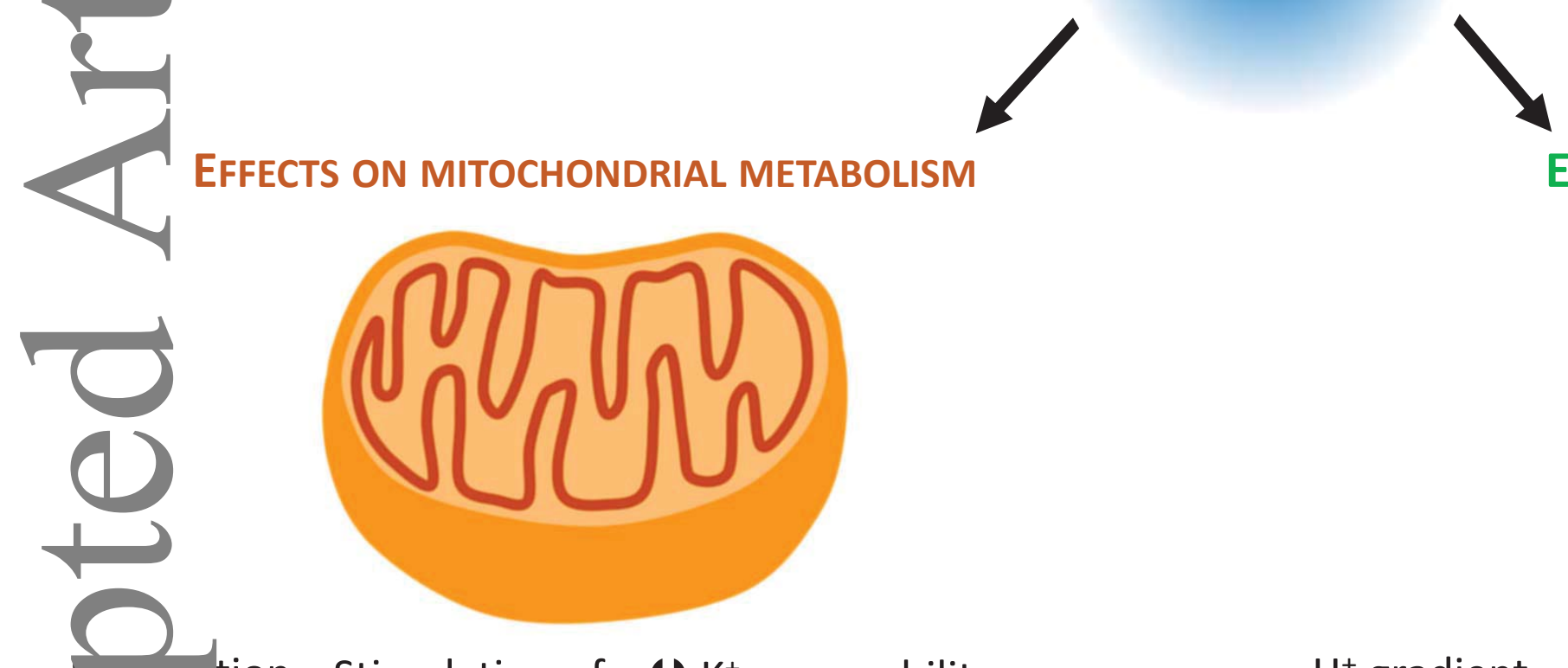

EFFECTS ON CHLOROPLAST METABOLISM

Jimluation Stimulation of $\mathrm{K}^{+}$permeability MPT of TCAP and

$\mathrm{F}_{0} \mathrm{~F}_{1}$ ATPases via ${ }^{\text {mito }} K_{\text {ATP }}$ $\mathrm{NDHs}$

C
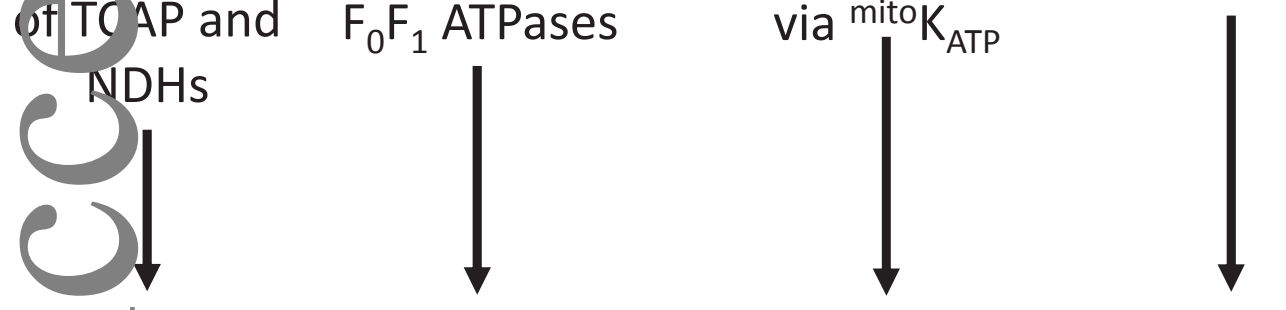

$\mathrm{H}^{+}$gradient

dissipation

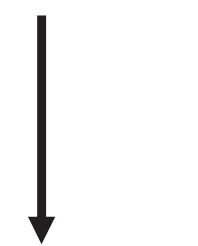

(1) Expression

ATP synthase

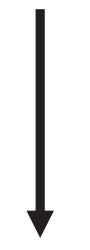

(1) NPQ

$\mathrm{Mg}^{2+}$ antagonist

Jecrease in electron pressure and increased ATP synthesis

Increased photochemical yield and ATP snthesis 